\title{
Solid-Liquid-Liquid Equilibria of the System Water, Acetonitrile, and Ammonium Bicarbonate in Multiphase Reacting Systems
}

\author{
Antonio Tripodi,* Francesco Conte, Alessandro Robbiano, Gianguido Ramis, and Ilenia Rossetti*
}

Cite This: Ind. Eng. Chem. Res. 2021, 60, 16791-16804

Read Online

ABSTRACT: The salting out of acetonitrile from water in the presence of ammonium bicarbonate was studied at atmospheric pressure from 4 to $35{ }^{\circ} \mathrm{C}$. The coexisting phases were analyzed independently with $\mathrm{H}^{1}$ nuclear magnetic resonance, ion chromatography, calorimetry, and titrations. The binodal region was described with semiempirical functions and with the UNIQUAC thermodynamic model. The critical composition at ambient temperature is given by $0.02 \mathrm{~g} / \mathrm{g}$ of salt and $0.58 \mathrm{~g} / \mathrm{g}$ of acetonitrile: at lower salt concentrations; this mixture is widely employed in liquid chromatography, thanks to the buffering properties of the bicarbonate. The separation of acetonitrile and water for extraction purposes, instead, is often obtained with other ammonium salts. These ternary equilibrium data can then be useful to develop extraction and analysis procedures at buffered, mildly alkaline $\mathrm{pH}$. In addition, this mixture can be encountered during the acetonitrile synthesis proposed from bioethanol and bioethylene, so these multiphase equilibria govern the separation and purification of acetonitrile in specific reactors that allow the recovery of ammonium bicarbonate as a valuable byproduct. Furthermore, the solubility of this salt in alcohols and its decomposition were investigated to target its

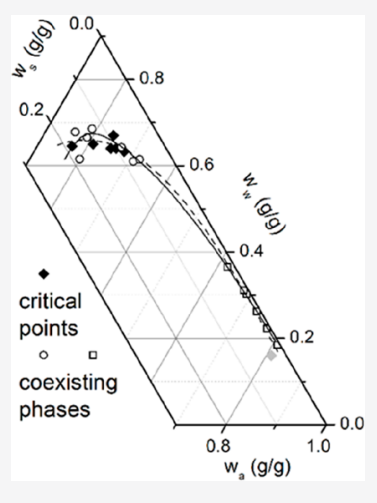
stability in multiphase reactors, extractors, and driers.

\section{INTRODUCTION}

Acetonitrile is a solvent of major importance for research experiments and for the pharmaceutical industry, ${ }^{1-4}$ but its separation from water cannot be achieved with one distillation unit, given the formation of an azeotrope, so usually a pressure swing ${ }^{5,6}$ or an extractive distillation ${ }^{3,6-8}$ technique is used. This passage is necessary when acetonitrile is produced, because water is a byproduct of the consolidate Sohio process, ${ }^{9}$ as well as of the oxidative routes sought by many researchers. ${ }^{10-15}$ All the more important, it is fundamental for the recovery and reuse of acetonitrile from effluents. $3,16-19$

Organic solvents ${ }^{20-22}$ and, more recently, ionic liquids ${ }^{23-25}$ or even newer molecules, ${ }^{26}$ have been used to increase the volatility of acetonitrile with respect to water, ${ }^{27,28}$ or to induce a liquid-liquid separation. ${ }^{29,30}$ This result could also be obtained without extracting agents, lowering the temperature, ${ }^{31-34}$ though this methodology seems more attractive for laboratory rather than for industrial purposes. The liquid-liquid transition induced by ionic compounds was first studied systematically by Renard, Oberg, Heichelheim, ${ }^{35-38}$ and Cannon ${ }^{39}$ and has since drawn the attention of other researchers, ${ }^{40-42}$ until the very recent experimental and theoretical studies by An et al. ${ }^{43}$ and Minglun et al. ${ }^{44}$ The IUPAC and NIST organizations have compiled an extended review of the acetonitrile-based mixtures yielding a phase transition. ${ }^{45}$

Because acetonitrile itself acts as an extractor for many organic molecules from water, the addition of inorganic salts is a widespread tool in many protocols: ${ }^{46-55}$ the analytes are brought in the light phase, whereas the ionic species remains with the water and does not interfere in the downstream steps.
Although the general procedure is consolidated, newer particular systems are continuously devised and tested. ${ }^{56,57}$ In this context, phase-splitting substances that can also affect the $\mathrm{pH}$ are of interest where proteins or other $\mathrm{pH}$-sensitive molecules are involved. ${ }^{46,58-60}$ For this reason, adding ammonium bicarbonate to acetonitrile-water eluents is foreseen in several HPLC and extraction procedures, even when a phase separation is not foreseen, because other salts could adjust the ionic strength without granting a buffering effect. $^{61-64}$ Selected reactions can be carried out in the homogeneous phase, achieving phase separation when needed through salting out. In this way, the reactor is dealt as a solidliquid-liquid multiphase one, needing the computing of phase equilibria to model its output.

Given this context, we are, however, not aware of any systematic test on the use of ammonium bicarbonate as a saltingout agent for acetonitrile. In their specific work about this salt as buffering agent for HPLC, Espada and Sagredo did not mention the possibility: ${ }^{65}$ probably these researchers, like others cited, never prepared eluents beyond the critical point. Also the solubility within solvents different from water has received little $^{66}$ or no attention, with the notable exception of ethanol:

Special Issue: CAMURE11-ISMR10

Received: June 14, 2021

Revised: July 31, 2021

Accepted: August 2, 2021

Published: September 1, 2021

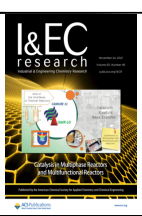


Table 1. List of the Tests and Analytical Tools Employed

\begin{tabular}{|c|c|c|c|}
\hline assay type & experiment & analysis method & main result \\
\hline qualitative & splitting of different mixtures & visual inspection & phase-split range \\
\hline \multirow[t]{5}{*}{$\begin{array}{l}\text { semi- } \\
\text { quantitative }\end{array}$} & $\begin{array}{l}\text { salt precipitation from different solvents and fast drying- } \\
\text { decomposition }\end{array}$ & thermogravimetric analysis & $\begin{array}{l}\text { salt-solvent mutual affinity, gross latent heat (with } \\
\text { respect to water) }\end{array}$ \\
\hline & density measure & $\begin{array}{l}\text { micropipette sampling and } \\
\text { weighing }\end{array}$ & phase densities \\
\hline & organic phase basic hydrolysis and back-titration & pHmetry, conductometry & approximate acetonitrile fraction \\
\hline & phase fast evaporation & thermogravimetric analysis & approximate water and acetonitrile fractions \\
\hline & & pHmetry, conductometry & salt fraction \\
\hline \multirow[t]{2}{*}{ quantitative } & phases analysis & ${ }^{1} \mathrm{H}$ NMR & acetonitrile fraction \\
\hline & & cation-exchange IC & salt fraction \\
\hline
\end{tabular}

Zhang et al. focused on the antisolvent effect of ethanol added to water, but did not measure the salt solubility in the pure alcohol. $^{67}$

Most studies regarding this salt, on the other hand, investigate more generally the thermodynamics of the $\mathrm{NH}_{3}-\mathrm{CO}_{2}$-water mixture, ${ }^{68-73}$ showing that ammonium bicarbonate is the predominant solid species when the stoichiometric ratio between $\mathrm{N}$ and $\mathrm{C}$ is $1: 1 .^{74,75}$ This system is of interest when ammonia is used as a $\mathrm{CO}_{2}$-capturing agent ${ }^{75-80}$ or when the salt itself is produced and marketed as a fertilizer alternative to urea. 81,82

Coming then to the recent studies on the production of acetonitrile by $\mathrm{C}_{2}$ substrate gas-phase ammoxidation, excess ammonia, water, and $\mathrm{CO}_{2}$ (from parasitic combustion) are commonly found among the reaction products. ${ }^{83,84}$ The precipitation of ammonium bicarbonate then presents itself as a natural option to purify the acetonitrile, which can be concentrated in a water-poor liquid phase leaving ammonia and $\mathrm{CO}_{2}$ (and most of the water) within the solid or at least in the aqueous liquid. ${ }^{85}$ Nguyen et al. proposed a novel liquid-phase route to acetonitrile in the presence of ammonium acetate, ${ }^{86}$ which is indeed a salting-out agent, ${ }^{57}$ but overlooked this possibility in their purification section design.

The scope of this work is to give a full qualitative account of the acetonitrile-water separation in the presence of ammonium bicarbonate at atmospheric pressure, together with the first quantitative treatment of the phenomenon. The study started after some experiments on ammonium bicarbonate drying from a mixed solvent, ${ }^{85}$ when a meniscus appeared within the liquor; in fact, acetonitrile behaves as an antisolvent toward ammonium bicarbonate, much in the same way as ethanol. To complete the survey, the solubility of ammonium bicarbonate in different solvents was reviewed and its sublimation heat was estimated.

\section{EXPERIMENTAL SECTION}

2.1. Sample Preparation. Acetonitrile HPLC-grade (>99.9\%), ethanol, and methanol reagent-grade (>99\%) were obtained by Sigma-Aldrich and used without further purification. Ammonium bicarbonate analytical-grade was obtained from Carlo Erba. Demineralized Milli-Q water was obtained by ion exchange (conductivity $<2 \mu \mathrm{S}$ ). Weighings took place on a Gibertini electronic scale balance and samplings were done with a micropipette.

The study of the phase separation of the ternary mixture is made of qualitative, semiquantitative and quantitative assays, according to Table 1. This workflow was at first made necessary by different instruments and premises scheduled availability, but granted a wider range of analytical results to be compared.
After the general conditions to achieve a liquid-liquid split were understood, different samples were prepared into plastic screwed vials and let rest overnight. When the phases had settled, their volumes were measured from the meniscus height (knowing the vial content at various levels). Then the phases were sampled with a micropipette, their weights recorded, and divided into aliquots for semiquantitative experiments and, eventually, more precise quantitative tests. The ambienttemperature tests were performed while monitoring the lab temperature, selecting the data obtained when it remained stable at $25{ }^{\circ} \mathrm{C}$. To work at higher temperatures, a thermal bath was used, while the low-temperature samples were placed into a fridge.

The critical points at room temperature $\left(25^{\circ} \mathrm{C}\right)$ were sought using a quick variant of the cloud-point method: ammonium bicarbonate-water solutions of known concentration were prepared and weighed into $3-5 \mathrm{~mL}$ vials, then pure acetonitrile was added with a micropipette $(50-100 \mu \mathrm{L}$ at a time $)$, and the solution was gently stirred after each addition, until a liquidliquid interface appeared just beneath the liquid-air one. The actual content of the vial was controlled by weighing after and before each addition. The experiment was repeated also adding little salt aliquots to preweighed acetonitrile-water mixtures, though this procedure showed to be less reliable. To explore the acetonitrile-rich end of the phase diagram, a saturated salt solution was added with a micropipette to pure acetonitrile, until a stable aqueous layer was seen at the vial bottom. In any case, the aliquots added each time to the binary solutions were small enough as to minimize the mixing enthalpy effect on temperature. The critical points at $35{ }^{\circ} \mathrm{C}$ were evaluated with the same procedure, but letting rest the vials for some minutes in the thermal bath after each weighing.

The salt solubility in saturated and solutions of the salt in water, ethanol, methanol, acetonitrile and water-acetonitrile were checked at different temperatures, both with the IC and with the back-titration methods. The decomposition was studied starting from samples of the pure salt (or after precipitating the salt from a solvent, centrifuging and filtering it), letting it dry and decompose over time, or accelerating the process by increasing the temperature.

2.2. Analysis. Unlike most inorganic salts, ammonium bicarbonate cannot be quantified via solvent evaporation and eventual weighing because it decomposes readily in the presence of water. ${ }^{87}$ Sutter and Mazzotti ${ }^{88}$ reported a benchmark procedure in several passages, based on the conversion of ammonium into ammonia at alkaline $\mathrm{pH}$, its distillation and absorption and eventual titration of the bicarbonate ions and ammonium ions separately. For this work, a simpler one-step procedure is proposed: $0.5-1 \mathrm{~mL}$ of sample is added to $5 \mathrm{~mL}$ of $\mathrm{NaOH} 1 \mathrm{M}$ (plus $0.3-0.5 \mathrm{~g}$ of $\mathrm{NH}_{4} \mathrm{HCO}_{3}$ as internal reference): 
the solution is then diluted and titrated with $\mathrm{HCl} 1 \mathrm{M}$. Several calibration trials showed that the loss of ammonia at the beginning of the titration was negligible (within the buret sensitivity-see also the Supporting Information).

The main drawbacks of this technique are (a) a relative shallow $\mathrm{pH}$-step between the residual $\mathrm{OH}$ neutralization and the $\mathrm{NH}_{3}-\mathrm{CO}_{3}$ buffers; (b) a very noisy response of the conductometer at the end of the $\mathrm{HCO}_{3}$ buffer, when $\mathrm{CO}_{2}$ bubbles develop, and, the $\mathrm{pH}$ meter remained unaffected. The bicarbonate anions are then quantified from the second buffer extension and subtracted from the first one to yield the ammonium; the deviations from the 1:1 ratio are taken as the error, every quantity is computed twice and mediated by using the $\mathrm{pH}$ curve and the conductometer segmented line. The technique proved fairly reliable and reproducible, even with the small quantities involved, and the buret sensitivity $(0.1 \mathrm{mmol})$ prevents to detect the salt traces in the organic phase. Figure S1 reports a calibration test.

The organic phase hydrolysis proved to be a robust method to establish the gross fraction of acetonitrile in the organic phase, in view of planning the due sample preparation for ${ }^{1} \mathrm{H}$ NMR measures. The procedure consists of adding $0.5-1.0 \mathrm{~mL}$ of light phase to $100 \mathrm{~mL}$ of water with $4 \mathrm{~g}$ of solid $\mathrm{NaOH}$ and let the solution boil for 3-4 h under reflux. The conversion of acetonitrile into sodium acetate is considered complete, thanks to the effective volatilization of ammonia. Finally $10-15 \mathrm{~mL}$ of the cooled reaction mixture are sampled, weighed, and backtitrated directly with $\mathrm{HCl}$, after adding a known amount of $\mathrm{AcONa} \cdot 3 \mathrm{H}_{2} \mathrm{O}$ (Fluka) as internal reference. This method has a limited accuracy due to (a) possible ammonia residues that interfere with the reaction completeness and with the final $\mathrm{pH}$ curve shape and (b) the limited buret sensitivity; its precision was shown to be satisfactory, as shown in Figure S2.

These two methodologies alone were in principle sufficient to carry out the whole analysis of the ternary system, but in practice more refined methods were needed for the following reasons:

(a) the ammonium-bicarbonate joint titration is not sensitive enough to detect the salt in the organic phase, which should be derived via the lever-rule only;

(b) as water is also evaluated indirectly by difference, this means increasing the error and, moreover, introducing a spurious correlation between the two results;

(c) when the system composition is such as to yield a solid phase, the practical difficulties in its purification and weighing made it very hard to establish a reliable salt balance;

(d) the acetonitrile detection after its conversion into acetate has an error as high as 10\%; moreover, it is unpractical to use this method for the aqueous phase, because the bicarbonate has roughly the same $\mathrm{pK}$ of the acetic acid.

The density measures (by volumetric sampling and weighing), especially for samples not at room temperature, cannot be considered fully quantitative because of (a) the unavoidable thermal drift and (b) the appreciable salt amount in the aqueous phase that would require a ternary preliminary calibration. For these reasons, they were not used to trace the phase diagrams but just to establish on a wider basis the difference between each phase.

The accurate quantification of acetonitrile in both phases was then obtained with ${ }^{1} \mathrm{H}$ NMR measures (as most common GC columns do not tolerate ammonia) using a Bruker Avance instrument. Unfortunately, organic deuterated solvents induce further acetonitrile-water separation, so $\mathrm{D}_{2} \mathrm{O}$ presented as the only viable ${ }^{1} \mathrm{H}$ NMR solvent for this system, which prevents water quantification. The protons belonging to ammonium and bicarbonate exchange all over the spectrum and become hidden within the signal baseline, as ascertained with trial measures. To quantify the acetonitrile fraction, we weighed the samples before and after the addition of ethanol, which thus provides the internal calibration signal and does not interfere with the acetonitrile-water miscibility. $\mathrm{D}_{2} \mathrm{O}$-acetontrile mixtures themselves are indeed unstable at low temperatures, ${ }^{34}$ but not in the conditions of the presented preparations and analysis.

The IC analyses were performed with a Metrhom 883 Basic IC Plus unit, equipped with a Metrosep C4 250/4.0 cationic column and calibrated with ammonium chloride solutions. This instrument has the sensitivity required to detect the salt in the organic phase, moreover its accuracy and fastness made it a valuable tool also to examine the aqueous solvents.

The thermogravimetric analysis was performed with a Mettler-Toledo TGA/DSC/3 + 1100 unit. This method can provide an estimation of the acetonitrile fraction and, moreover, it is in principle capable to yield independently the water fraction, thanks to the different latent heats of the two chemicals. ${ }^{89}$ However, as explained in the next sections, this technique cannot be used alone to examine the mixtures because the heat signal is not as accurate as the mass measure.

\section{DATA ELABORATION}

The chemical shifts of the ${ }^{1} \mathrm{H}$ NMR measures are reported in Figure S3. The moles of acetonitrile (a) and ethanol (e) within the tube simply relates to their peaks areas (PA) and to their relative quantities as

$$
\frac{n_{\mathrm{a}}}{n_{\mathrm{e}}}=\frac{\mathrm{PA}_{\mathrm{a}}}{\mathrm{PA}_{\mathrm{e}-\mathrm{CH}_{3}}} \Rightarrow \frac{n_{\mathrm{a}} P M_{\mathrm{a}}}{n_{\mathrm{e}} P M_{\mathrm{e}}}=\frac{w_{\mathrm{a}} m_{\text {liq }}}{m_{\mathrm{e}}}
$$

The analysis of the TGA data is more complex, and is best illustrated referring to a binary water-acetontrile mixture. First, the total heat released during the experiment represents the specific latent heat $\lambda\left(w_{\mathrm{a}}\right)$ of the system (expressed as a function of the acetonitrile fraction prior to the sample evaporation), so after performing the due calibrations (see Figure S4), the normalized heat signal $\Delta h / \Delta t$ and the normalized mass differential signal $\Delta w / \Delta t$ provided by the apparatus can be integrated as

$$
\begin{aligned}
\int_{0}^{\text {end }} \frac{\Delta h}{\Delta t} \mathrm{~d} t & =\Delta h \\
& =\int_{0}^{\text {end }} \lambda(w) \frac{\Delta w}{\Delta t} \mathrm{~d} t+c_{\mathrm{p}} \int_{0}^{\mathrm{end}} w(t) \frac{\Delta T}{\Delta t} \mathrm{~d} t
\end{aligned}
$$

where $\frac{\Delta T}{\Delta t}$ is the fixed imposed heating ramp. Being the sensible heat contribution much less important than the latent heat, $\Delta h$ $\cong \lambda\left(w_{\mathrm{a}}\right)$, which directly yields the acetonitrile fraction once $\lambda$ $\left(w_{\mathrm{a}}\right)$ is tabulated from reference data (Figure S4). If the mixture is actually binary, as is to a good approximation a typical organic phase, this constitutes also a direct measure of the water quantity. ${ }^{89,90}$ The aqueous phase cannot be treated under this assumption, as explained in the next sections.

The consistency of the phase equilibrium data was evaluated with the Othmer-Tobias, ${ }^{91}$ Bachman, ${ }^{92}$ and Hand ${ }^{93}$ tests, which verify the existence of a linear correlation between the variables defined respectively in eqs 3,4 , and 5 : 


$$
\begin{aligned}
& \ln \frac{1-w_{\mathrm{a}}^{\mathrm{II}}}{w_{\mathrm{a}}^{\mathrm{II}}}=p 1+p 2 \ln \frac{1-w_{\mathrm{s}}^{I}}{w_{\mathrm{s}}^{I}} \\
& w_{\mathrm{w}}^{\mathrm{II}}=p 1+p 2 \frac{w_{\mathrm{w}}^{\mathrm{II}}}{w_{\mathrm{s}}^{\mathrm{I}}} \\
& \frac{w_{\mathrm{w}}^{\mathrm{I}}}{w_{\mathrm{s}}^{\mathrm{I}}}=p 1+p 2 \frac{w_{\mathrm{w}}^{\mathrm{II}}}{w_{\mathrm{a}}^{\mathrm{II}}}
\end{aligned}
$$

The binodal curves were interpolated according to the HlavatyLetcher implicit function ${ }^{94,95}$ and the Merchuk exponential fit, ${ }^{96}$ eqs 6 and 7. For the interpolation, both the phase-split data and the critical point search data were used.

$$
\begin{aligned}
& w_{\mathrm{w}}=\mathcal{L}\left(w_{\mathrm{a}}, w_{\mathrm{w}}\right)=A\left[\left(1-\frac{w_{\mathrm{a}}+w_{\mathrm{w}} / 2}{\Delta w_{\mathrm{a}}}\right)^{B}\right]\left(\frac{w_{\mathrm{a}}+w_{\mathrm{w}} / 2}{\Delta w_{\mathrm{a}}}\right)^{C} \\
& w_{\mathrm{a}}=\mathcal{M}\left(w_{\mathrm{s}}\right)=D+A e^{-\left(B \sqrt{w_{\mathrm{s}}}+C w_{\mathrm{s}}^{3}\right)}
\end{aligned}
$$

The plait points of the coexistence curves can be evaluated with different methods:

(a) the binodal line is represented with one of the variable changes in eqs 3-5 (assuming that $w^{\mathrm{I}}=w^{\mathrm{II}}$ ) and is then intersected with the line parametrized by $p 1, p 2$;

(b) as proposed by Merchuk et al., ${ }^{96}$ the tie-lines slopes are expressed as an empirical function $s\left(w_{\mathrm{s}}^{\mathrm{I}}\right)=\frac{\Delta w_{\mathrm{a}}^{\mathrm{I}-I I}}{\Delta w_{\mathrm{s}}^{\mathrm{III}}}$, then it is solved the equality: $s\left(w_{\mathrm{s}}^{\mathrm{I}}\right)=\frac{\mathrm{d} \mathcal{M}\left(w_{\mathrm{s}}\right)}{\mathrm{d} w_{\mathrm{s}}}$;

(c) the method of the conjugation by Coolidge; ${ }^{35}$

(d) the method of the rectilinear diameters. ${ }^{97}$

The interpolation of the data with a thermodynamic model, instead, was based on the coexisting phases only: the UNIQUAC model was chosen, with the formulation given by Anderson and Prausnitz, ${ }^{98}$ with details reported in section D in the Supporting Information.

The extended electrolyte model ${ }^{99}$ was not used because the treatment of a quaternary mixture was judged outside the scope of this work, considering that the number of parameters that can be reliably regressed is limited by the available data. This implicit treatment of the electrostatic energy term as a modifier of the salt-free pair interaction parameters was developed by Choi and co-workers. ${ }^{100}$ The procedure followed to obtain the parameters from the liquid-liquid data collection was first set up by Sorensen et al. ${ }^{101}$ and lately reviewed by Tomassetti et al. ${ }^{102}$ (see also references therein), with only minor modifications.

Other details, namely, (a) the alignment of the calculated phases with the average experimental system compositions, (b) the thermodynamic consistency of the excess Gibbs energy along a tie-line, and $(c)$ the strategies to optimize $f$ and $F$ are found in the referenced works.

Most of the data treatment and fitting were carried out using Microcal Origin ver. 8.5; the UNIQUC parameters regression was performed using Mathworks Matlab R2020b.

\section{RESULTS AND DISCUSSION}

4.1. Component Partition. An evaluation of the data according to the lever-rule is presented in the Supporting Information Table S1. With respect to other systems, there are two aspects that make the analysis more difficult: a) the aqueous phase cannot be weighed directly when the salt is oversaturated, but b) the filtration and drying of the solid does not provide accurate results, because a non-negligible amount of ammonium bicarbonate is lost together with the moisture in the short term. Therefore, when the system presents a solid phase, the aqueous phase can be calculated only via the acetonitrile or salt mass balances, otherwise the mass balances can provide a crosscheck of the direct weighing:

$$
\begin{aligned}
& m^{\mathrm{I}} w_{\mathrm{a}}^{I}=m^{0} w_{\mathrm{a}}^{0}-m^{\mathrm{II}} w_{\mathrm{a}}^{\mathrm{II}} \\
& m^{\mathrm{I}} w_{\mathrm{s}}^{\mathrm{I}}=m^{0} w_{\mathrm{s}}^{0}-m^{\mathrm{II}} w_{\mathrm{s}}^{\mathrm{II}}(\text { solid not present }) \\
& m^{\mathrm{I}}\left(w_{\mathrm{s}}^{\mathrm{I}}-1\right)=m^{0}\left(w_{\mathrm{s}}^{0}-1\right)-m^{\mathrm{II}}\left(w_{\mathrm{s}}^{\mathrm{II}}-1\right)(\text { solid present })
\end{aligned}
$$

For the organic phase, it is always possible to evaluate the consistency between the recorded weight, the volume (measured before the sampling), and the estimated density.

The density chart (Figure 1) shows that the median and the mean values follow the expected trend, with the exception of the

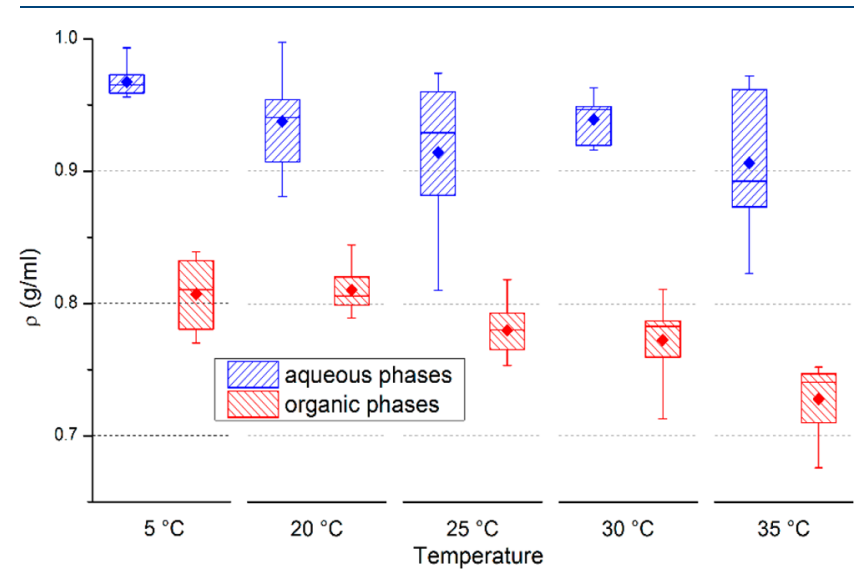

Figure 1. Box plot of the sample densities (considering also other tests respect to those used for the phase diagrams). The box body goes from the 25 th to the 75 th percentile, the midrule represents the median, the diamond marks the mean and the whiskers the min-max.

data collected at $30{ }^{\circ} \mathrm{C}$. The pipet sampling and weighing method, in the absence of a tight temperature control, cannot give precise information but can easily discriminate one phase from the other.

Figures 2 and 3 present, respectively, the extraction efficiencies of this salting out, for solid-liquid-liquid systems and for liquid-liquid ones. In the first case, is necessary to start from a solution with at least $55 \%$ acetonitrile (by weight) to obtain as much organic phase as aqueous; in the second case, fixing the acetonitrile content in the liquid at $0.5 \mathrm{~g} / \mathrm{g}$, one has to add ammonium bicarbonate up to $7 \%$ (of total weight) to achieve that condition. This composition, corresponding to an acetonitrile volume fraction of $\sim 63-64 \%$ in the liquid, is the one for which the organic:aqueous volume ratio is always higher than the starting acetonitrile:water one. The density of acetonitrilewater solutions is approximately a linear function of the weight fractions (see also Figure S5 and refs 103-105), so the volumes can be treated as additive in a mass-fraction reference system. The second graph also lets us conclude that the salt saturation does not need reached to maximize the extraction efficiency. Notice that the data dispersion along the $y$-axis (i.e., multiple organic:aqueous partitions achieved for the same ionic strength or initial acetonitrile content) comes from the fact that these 


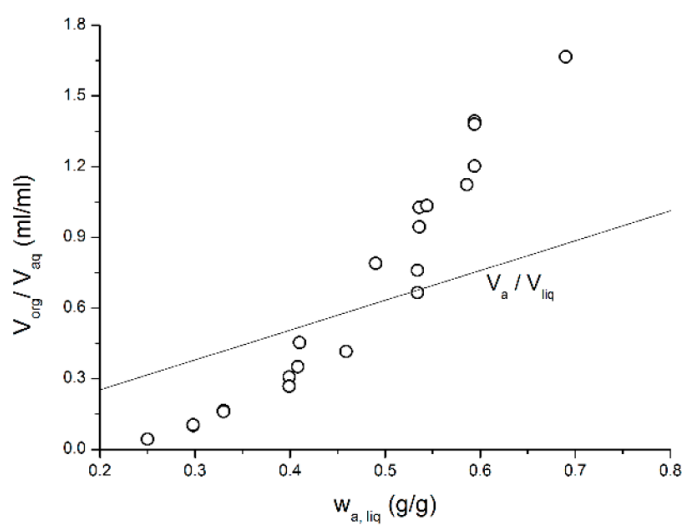

Figure 2. Organic:aqueous phase volume ratio obtained by supersaturated solutions with respect to the acetonitrile weight fraction of the original liquid. The line represents the acetonitrile volume fraction in the original liquid.

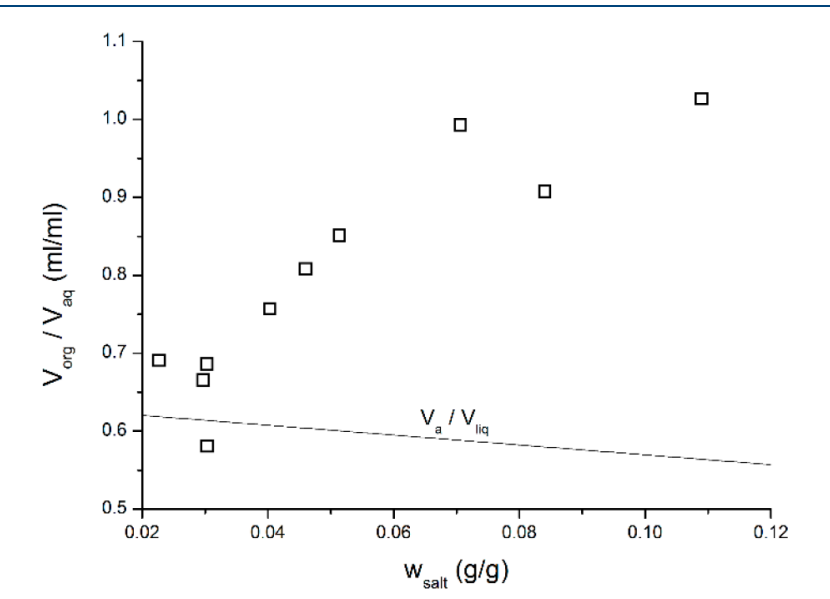

Figure 3. Organic:aqueous phase volume ratio obtained by undersaturated liquid solutions with a fixed acetonitrile content of $0.5 \mathrm{~g} / \mathrm{g}$, with respect to the overall salt weight fraction. The line represents the acetonitrile volume fraction in the original liquid.

results are presented over all the temperature range investigated (from $4{ }^{\circ} \mathrm{C}$ above $35^{\circ} \mathrm{C}$ ).

4.2. Phase Coexistence and Phase Diagrams. The relevant phase-split results could be achieved only with the full quantitative assay of the organic phases via IC, because the titration method was not sensitive enough to detect the salt traces in them, so the coexistence lines and the theoretical interpolation are based on this data subset (Table 2).

The results of the consistency tests are reported in Figures S6-S8 and in Table 3. The data at $25{ }^{\circ} \mathrm{C}$ suffer a greater dispersion, probably because at this temperature the systems are neither all saturated (as at $4{ }^{\circ} \mathrm{C}$ ) nor all undersaturated (as at 35 ${ }^{\circ} \mathrm{C}$ ), with differences in the equilibration times and on the salt quantities detected by the IC. The data at $4{ }^{\circ} \mathrm{C}$ pass the Bachman test, whereas the Othmer-Tobias one reveals one misaligned point (see the Supporting Information): this collection presents the problem of a very narrow operative margin between the salt saturation and the critical point, which makes all the aqueous phases align at very similar salt concentrations. The Hand formula gives the worst results for the more problematic data sets, because it takes into account only the salt (affected by higher error:signal ratios) and the water (measured indirectly), not the more reliable acetonitrile ${ }^{1} \mathrm{H}$ NMR values. The data at $35{ }^{\circ} \mathrm{C}$ pass all the tests. Nevertheless, these correlations depend on the systems for which they were originally developed and similarly unsatisfactory fits for acetonitrile-water-salt mixtures were already reported. ${ }^{37}$

Figures 4 and 5 show the experimental critical points and binodal curves, whereas the phase diagrams, each with the best interpolations as described below, are shown in Figures 6-8. The tie-lines at ambient temperature and at $35^{\circ} \mathrm{C}$ develop regularly, whereas those at $4{ }^{\circ} \mathrm{C}$ cross each other at low salt values. In this condition, in fact, the margin to variate the ionic strength maintaining under-saturation is too small, and so the three experiments nearer to the critical point behave as repetitions.

The critical points were evaluated with the conjugation line method, which is more robust in the context of these data, using in turn the Merchuk interpolation or the UNIQUAC calculation for the binodal line, as reported in Table 4. The Merchuk slope method, as well as the rectilinear diameter method, respectively imply an univocal choice for the binodal and a tight lever-rule balance, whereas the methods based on a coordinate change would be biased whenever the relative tests are not fully satisfied. A review in the case of the data at $35{ }^{\circ} \mathrm{C}$ is present in Figure S9. For consistency, the conjugation method with respect to the UNIQUC binodal was adopted starting from the UNIQUACcalculated phases: the estimation is then affected, for the data set at $35{ }^{\circ} \mathrm{C}$, by the underestimation of the acetonitrile content for three organic phases. The Merchuk interpolation of the binodal is likely more reliable, though theoretically less correct: the salt critical quantities estimated in this way, in fact, are much nearer to the minimum quantities used in practice to make the liquid mothers split.

The parametrization for the binodal curves (represented in Figure 9) is presented in Table S2, whereas Figure 10 reports the overall result of the UNIQUAC interpolation (Table S3). The Hlavaty-Letcher function does not guarantee a convex shape of the binodal curve over all the range and interpolates the aqueous phases with a broader profile, whereas the Merchuk function and UNIQUAC model introduce a sharper bend.

These two latter kinds of fit also suggest that the acetonitrile content in the aqueous phase is not monotonously decreasing (increasing the salt content) at $35^{\circ} \mathrm{C}$. This "bending" of the phase diagram was originally ${ }^{37}$ and lately ${ }^{44}$ observed in tests with lithium chloride, but in our case there were not enough data collected in this region to give a strong confirmation.

Over $35{ }^{\circ} \mathrm{C}$, only salt-titration data (for the aqueous phase) were available, and the accepted results were used to trace the coexistence region of Figure 11, reporting data at $\sim 40{ }^{\circ} \mathrm{C}$ that are consistent with the other observed phase diagrams.

4.3. Salt Solubility and Thermal Properties. The salt solubility in water (Figure 12), measured both with the IC and titration method, ranges from $0.1 \mathrm{~g} / \mathrm{g}$ at $4{ }^{\circ} \mathrm{C}(1.41 \mathrm{~m})$ to $0.15 \pm$ $0.02 \mathrm{~g} / \mathrm{g}(2.23 \pm 0.40 \mathrm{~m})$ at $25^{\circ} \mathrm{C}$; in this latter case, the titration data are more dispersed because of the higher error:signal ratio. At $35{ }^{\circ} \mathrm{C}$ the samples preparation is complicated by the longer equilibration times needed, since the initial salt content to grant the saturation is almost doubled and in this case the two methods show lower agreement. A comparison with the experiments of Sutter and Mazzotti ${ }^{88}$ (and other values referenced therein), who fixed a solubility of $2.97 \mathrm{~m}$ (i.e., 0.19 $\mathrm{g} / \mathrm{g}$ ) at $25^{\circ} \mathrm{C}$, suggests that the maximum values obtained in this work are probably the more reliable (see also the Figure S10). Measuring the salt solubility in mixed acetonitrile-water liquids outside the three-phase coexistence region, a systematic effect of the acetonitrile content cannot be detected (Figure S11). Other 
Table 2. Phase-Split Results for the Acetontrile-Water-Ammonium Bicarbonate System ${ }^{a}$

\begin{tabular}{|c|c|c|c|c|c|c|c|}
\hline \multirow[b]{2}{*}{ ID } & \multirow[b]{2}{*}{$T\left({ }^{\circ} \mathrm{C}\right)$} & \multicolumn{6}{|c|}{$(g / g)$} \\
\hline & & $w_{\mathrm{a}}^{0}$ & $w_{\mathrm{s}}^{0}$ & $w_{\mathrm{a}}^{\mathrm{I}}$ & $w_{\mathrm{s}}^{I}$ & $w_{\mathrm{a}}^{\mathrm{II}}$ & $w_{\mathrm{s}}^{\mathrm{II}}$ \\
\hline CAQ05431 & 4 & 0.475 & 0.050 & 0.25 & 0.0572 & 0.81 & 0.00537 \\
\hline CAQ05432 & 4 & 0.480 & 0.040 & 0.22 & 0.0537 & 0.81 & 0.00161 \\
\hline CAQ05601 & 4 & 0.450 & 0.100 & 0.22 & 0.0660 & 0.84 & 0.00140 \\
\hline CAQ05528 & 4 & 0.485 & 0.030 & 0.27 & 0.0500 & 0.79 & 0.00200 \\
\hline CAQ05529 & 4 & 0.489 & 0.023 & 0.30 & 0.0400 & 0.7 & 0.00874 \\
\hline CAQ05619 & 4 & 0.484 & 0.032 & 0.28 & 0.0510 & 0.75 & 0.00280 \\
\hline CAQ05430 & 4 & 0.445 & 0.109 & 0.23 & 0.0620 & 0.84 & 0.00200 \\
\hline CAQ05201 & 25 & 0.480 & 0.038 & 0.30 & 0.079 & 0.67 & 0.00972 \\
\hline CAQ05203 & 25 & 0.464 & 0.071 & 0.21 & 0.107 & 0.71 & 0.00568 \\
\hline CAQ05207 & 25 & 0.431 & 0.138 & 0.22 & 0.0975 & 0.75 & 0.00542 \\
\hline CAQ05206 & 25 & 0.451 & 0.099 & 0.22 & 0.119 & 0.78 & 0.00461 \\
\hline CAQ05322 & 25 & 0.485 & 0.022 & 0.40 & 0.044 & 0.62 & 0.0110 \\
\hline SAQ01320 & 25 & 0.550 & 0.030 & 0.38 & 0.0469 & 0.63 & 0.0136 \\
\hline CAQ05602 & 25 & 0.420 & 0.168 & 0.19 & 0.123 & 0.75 & 0.00630 \\
\hline CAQ05208 & 35 & 0.474 & 0.051 & 0.19 & 0.125 & 0.73 & 0.00768 \\
\hline CAQ05109 & 35 & 0.450 & 0.099 & 0.16 & 0.162 & 0.77 & 0.00546 \\
\hline CAQ05311 & 35 & 0.477 & 0.046 & 0.31 & 0.0801 & 0.69 & 0.00796 \\
\hline CAQ05325 & 35 & 0.480 & 0.040 & 0.32 & 0.0659 & 0.62 & 0.0152 \\
\hline CAQ05426 & 35 & 0.439 & 0.121 & 0.20 & 0.185 & 0.81 & 0.00586 \\
\hline CAQ05527 & 35 & 0.465 & 0.071 & 0.27 & 0.0874 & 0.68 & 0.00890 \\
\hline CAQ05603 & 35 & 0.458 & 0.084 & 0.19 & 0.145 & 0.77 & 0.00750 \\
\hline
\end{tabular}

${ }^{a}$ Superscript 0 indicates the overall system composition.

Table 3. Results of the Linear Fits to the Consistency Test. Bold Values Represent Passed Tests (F > 100)

\begin{tabular}{llllrc}
\multicolumn{1}{c}{ test } & data set & \multicolumn{1}{c}{$\mathrm{p} 1$} & \multicolumn{1}{c}{$\mathrm{p} 2$} & \multicolumn{1}{c}{$R^{2}$} & F-value \\
Othmer-Tobias & $4{ }^{\circ} \mathrm{C}$ & -6.015 & 1.624 & 0.882 & 45.7 \\
& $25{ }^{\circ} \mathrm{C}$ & -2.318 & 0.6014 & 0.827 & 29.6 \\
& $35{ }^{\circ} \mathrm{C}$ & -2.472 & 0.7280 & .952 & $\mathbf{1 1 7}$ \\
Hand & $4{ }^{\circ} \mathrm{C}$ & 3.146 & 0.4294 & 0.776 & 21.8 \\
& $25{ }^{\circ} \mathrm{C}$ & 3.009 & 1.072 & 0.822 & 28.8 \\
\multirow{3}{*}{ Bachman } & $35{ }^{\circ} \mathrm{C}$ & 2.872 & 1.123 & $\mathbf{. 9 7 7}$ & $\mathbf{2 5 9}$ \\
& $4{ }^{\circ} \mathrm{C}$ & 0.09106 & 0.02855 & $\mathbf{. 9 6 5}$ & $\mathbf{1 6 4}$ \\
& $25{ }^{\circ} \mathrm{C}$ & 0.2059 & 0.02043 & 0.855 & 36.4 \\
& $35{ }^{\circ} \mathrm{C}$ & 0.1671 & 0.03716 & $\mathbf{. 9 5 1}$ & $\mathbf{1 1 9}$ \\
\hline
\end{tabular}

characteristics of the titration method in general are in Figures S12 and S13.

The solubility in other pure solvents, in this case, ethanol and methanol, is shown in Figure 13. Methanol values are comparable to the water ones (except than in the cold mixture), whereas acetonitrile and ethanol behave similarly and their solvation capability is 1 order of magnitude smaller.

The different affinities of ammonium bicarbonate toward different solvents can be appreciated by also analyzing the salt drying and decomposition trends. When the salt is mixed with acetonitrile, then centrifuged and filtered, the residual liquid evaporates at room temperature within minutes, whereas the salt goes on losing weight over days because the atmospheric moisture mediates the ammonium and bicarbonate conversion into ammonia and carbon dioxide, ${ }^{106}$ as shown in Figure 14. If the same procedure is repeated starting from an oversaturated water solution, the initial drying is slower (because of the higher latent heat of water), but then the damp salt undergoes a quick decomposition releasing much of its weight along with the still evaporating water. In this case, the long-term decomposition in air seems slower, probably because, under free convection

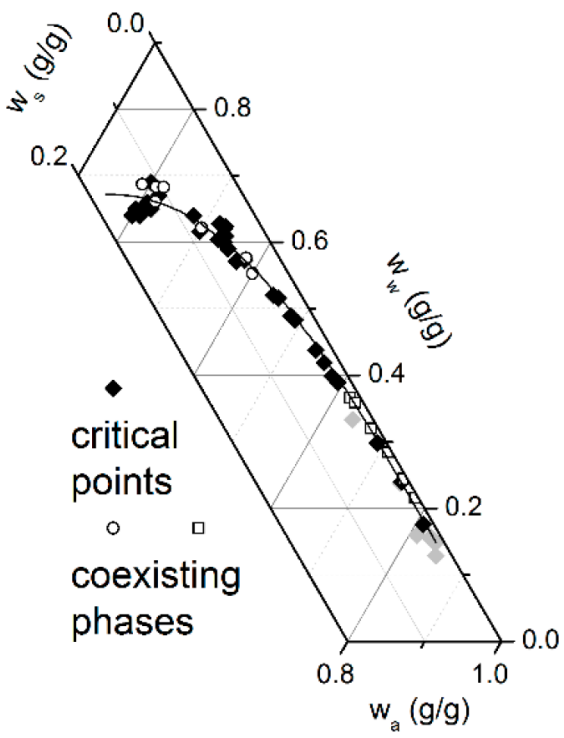

Figure 4. Critical points at $25{ }^{\circ} \mathrm{C}$. Filled diamonds: critical points dedicated tests; empty circles and squares: phases coexisting after a salting out. Lines: interpolated binodal curves.

conditions, the sublimation speed depends on the residual solid rather than the air humidity and temperature.

The use of a TGA unit gives a deeper insight into this phenomenon, on a much shorter time scale. Figure 15 shows that pure ammonium bicarbonate or that refiltered from acetonitrile behaves essentially in the same way, with a minor delay in the decomposition of the wet salt, probably because of its higher thermal inertia at the process' beginning. The salt precipitated from water carries instead a substantial moisture fraction (about 30 wt \% on wet basis) visible in the double-zone trend and all the more as an additional peak in the decomposition speed. With the water evaporation taking less 


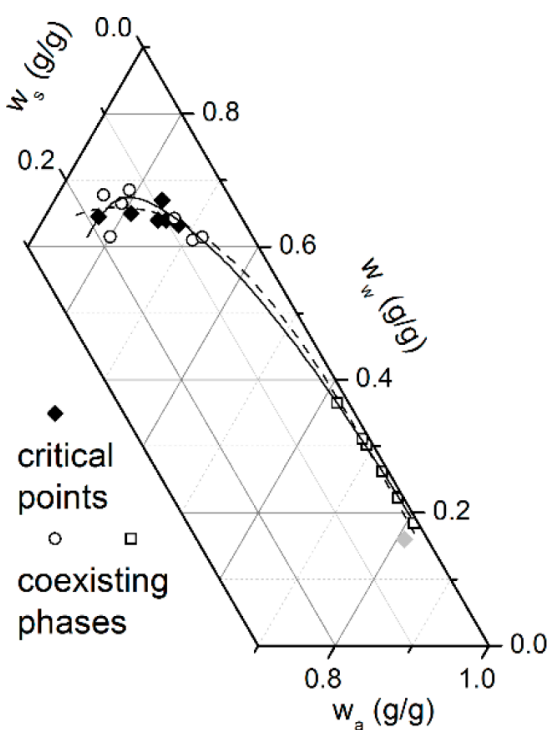

Figure 5. Critical points at $35{ }^{\circ} \mathrm{C}$. Filled diamonds: critical points dedicated tests; empty circles and squares: phases coexisting after a salting out. Lines: interpolated binodal curves.

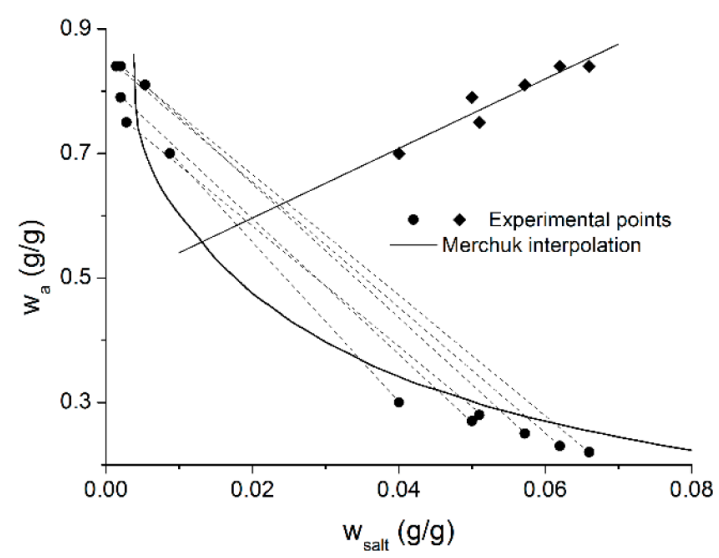

Figure 6. Phase diagram at $4{ }^{\circ} \mathrm{C}$. The three tie-lines obtained with an overall salt concentration of $2.5-3.5 \%$ are misaligned, because the driving force of the salting out has a so little variation as to yield very similar phase-splits, differing then for random sampling/analysis errors. This is partly true also for the systems with more than $4 \%$ salt, which share a substantially common organic phase.

than $10 \mathrm{~min}$ (instead of more than $1 \mathrm{~h}$ as in the room conditions experiment), the solid decomposition during this phase is much less important. The noise in the derivative signal above $100{ }^{\circ} \mathrm{C}$ can be attributed to the fact that (a) the water released from the bicarbonate decomposition is now oversaturated and tends to flash, and (b) the still intact solid melts.

Coming back to the ternary system, the thermal signal of the TGA can help to characterize the pure substances. In particular, as shown in Figure 16, the latent heats of water and acetonitrile retrieved from the cross-check of the thermal and weight signals are underestimated by $30 \%$; this error is nonetheless systematic and it can be taken into account as an instrumental calibration factor. The ammonium bicarbonate apparent sublimation heat is not distinguishable from the apparent evaporation heat of water, in this kind of charts.

If the analysis based on the evaporation kinetic ${ }^{107-109}$ is instead applied, by evaluating the function: $\ln \left(\frac{\Delta m}{\Delta t}\right)-\ln \left(\frac{1}{T}\right)=A-\frac{\lambda}{R T},{ }^{110}$ then the correct latent heats

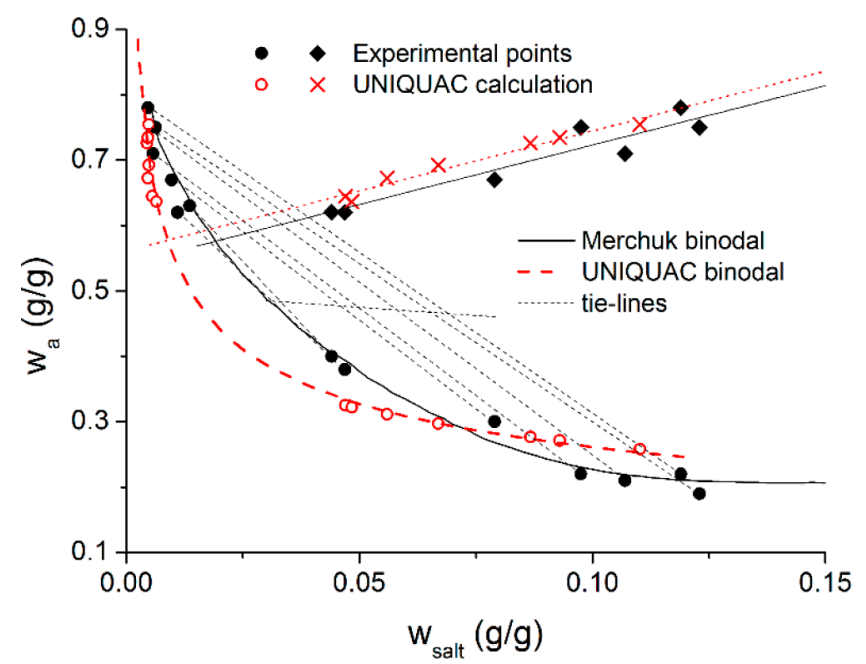

Figure 7. Phase diagram at $25{ }^{\circ} \mathrm{C}$. Filled circles: aqueous and organic phases; diamonds: aqueous-phase salt values related to the organicphase acetonitrile ones (used to identify the plait-point with the conjugation method); empty circles and crosses: the same, but with UNIQUAC-calculated phases.

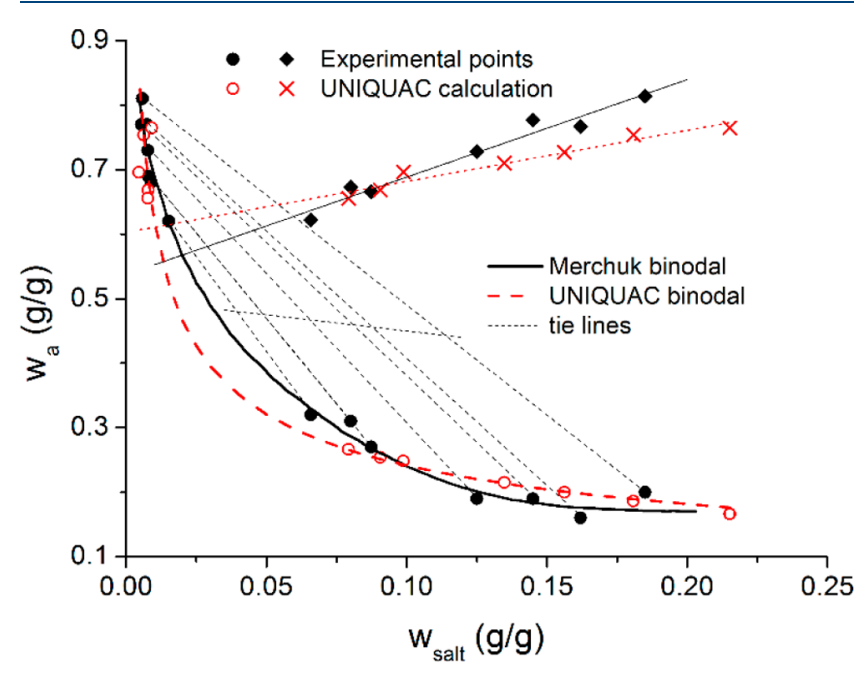

Figure 8. Phase diagram at $35^{\circ} \mathrm{C}$. The UNIQUAC calculation deviates from the experiments at high salt content, underestimating the maximum acetonitrile fraction in the light phase: this induces a lowbend in the linear fit used to calculate the plait-point.

Table 4. Critical Points for the Acetonitrile-WaterAmmonium Bicarbonate System at Ambient Pressure

\begin{tabular}{cccccc} 
& \multicolumn{5}{c}{$(\mathrm{g} / \mathrm{g})$} \\
\cline { 2 - 3 }$T^{\circ} \mathrm{C}$ & \multicolumn{2}{c}{ Merchuck binodal } & & \multicolumn{2}{c}{ UNIQUAC binodal } \\
\cline { 2 - 3 } \cline { 5 - 6 } & $w_{\mathrm{s}}$ & $W_{\mathrm{a}}$ & & $w_{\mathrm{s}}$ & $W_{\mathrm{a}}$ \\
25 & 0.0132 & 0.559 & & & 0.577 \\
35 & 0.0192 & 0.576 & & 0.00924 & 0.611 \\
\hline
\end{tabular}

of the acetonitrile and water can be retrieved (see Figure 17) also in this kind of experiments on open crucibles, thanks to the higher reliability and precision of the microbalance. From this analysis, the sublimation heat of ammonium bicarbonate results to be not less than $77.9 \mathrm{~kJ} / \mathrm{mol}$ at the beginning of the decomposition, but shifts later to the lower value of $41.7 \mathrm{~kJ} / \mathrm{mol}$. The direct decomposition reaction is $\mathrm{NH}_{4} \mathrm{HCO}_{3}(\mathrm{~s}) \rightarrow \mathrm{NH}_{3}(\mathrm{~g})$ 

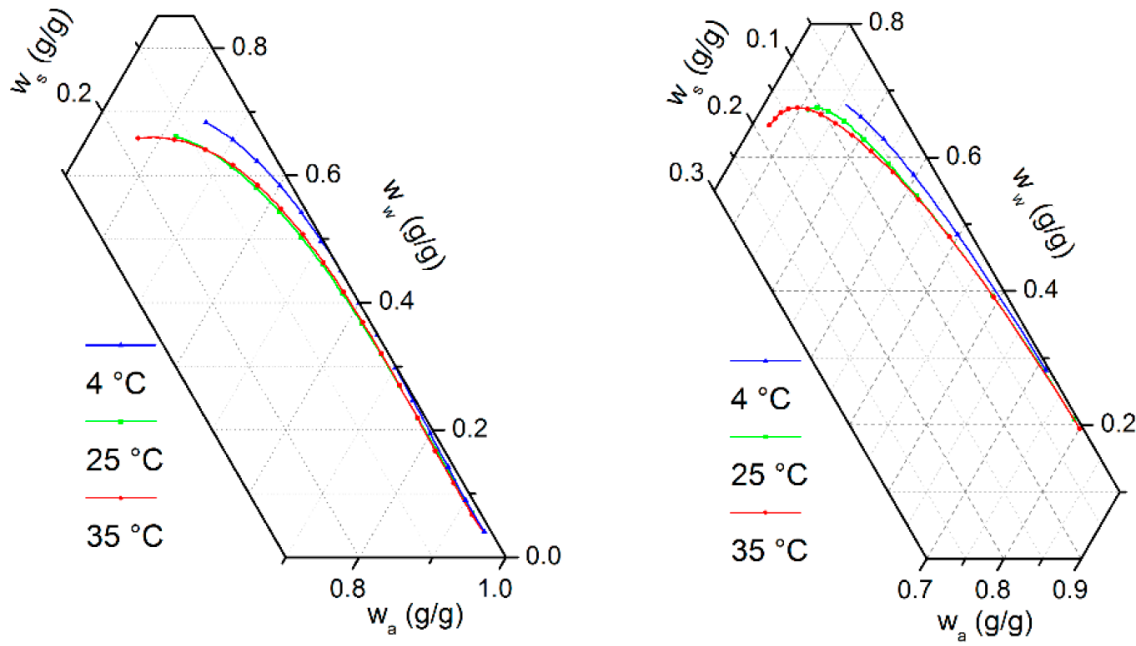

Figure 9. Binodal curves at different temperatures according to function 6 (left) and 7 (right).

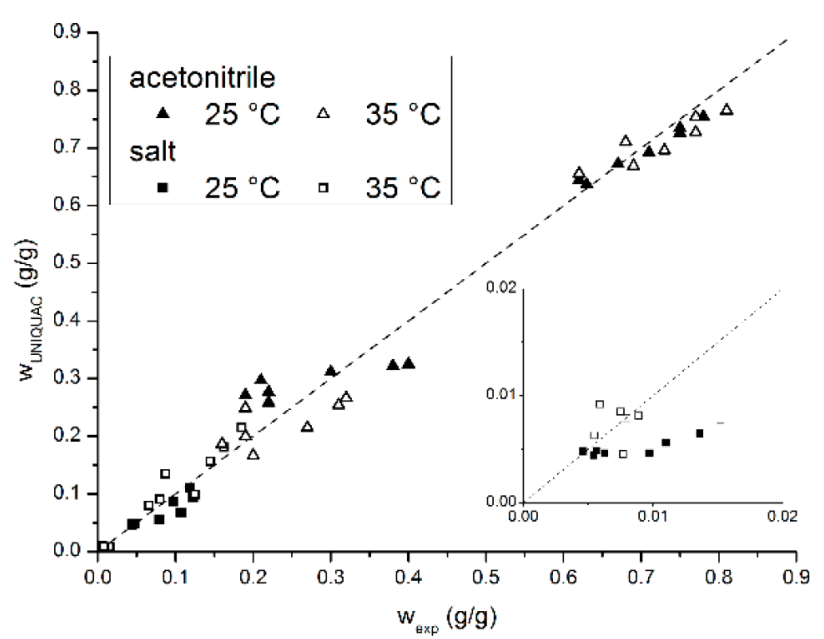

Figure 10. Parity plot for the UNIQUAC description of the system.

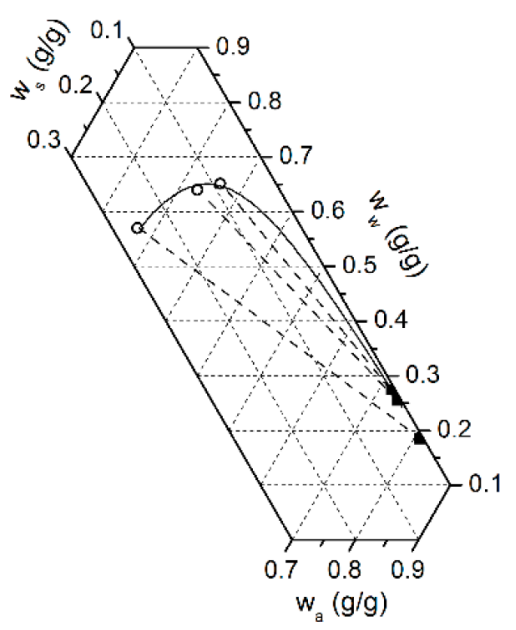

Figure 11. Phase diagram at $40-43^{\circ} \mathrm{C}$. Salt values in the organic phase were not available and so were fixed at $0.05 \mathrm{M}$ (sensitivity limit of the titration method).

$+\mathrm{CO}_{2}(\mathrm{~g})+\mathrm{H}_{2} \mathrm{O}(\mathrm{g})$ with $\Delta h=168 \mathrm{~kJ} / \mathrm{mol}$ (calculated using the parameters by Que et al. ${ }^{111}$ and by Darde et al. $\left.{ }^{70}\right)$. Though we are not aware of experimental data for the heat of sublimation in the literature, Figure S14 shows the reported the findings of

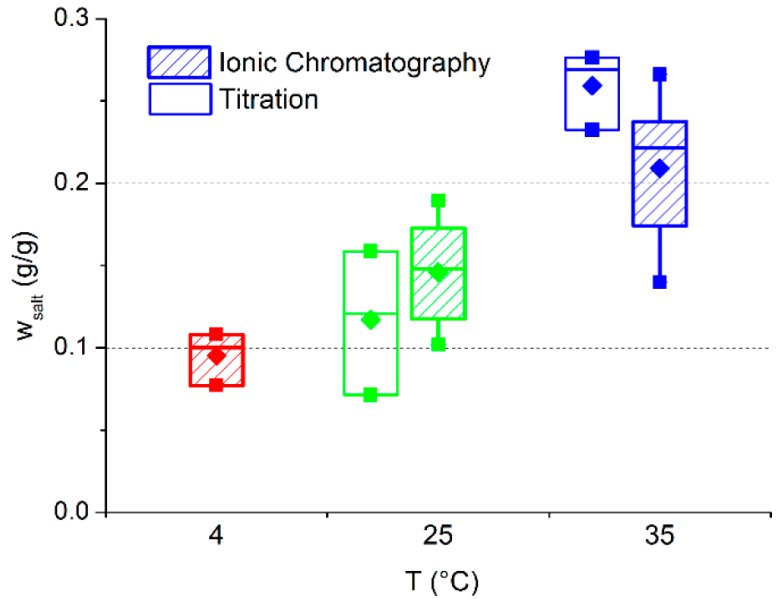

Figure 12. Box chart for the water solubility data: the diamond indicates the mean, the boxes dimensions, the center line represents the 25th-50th-75th percentiles, the whiskers the 10th and 90th, and the squares the maxima and minima.

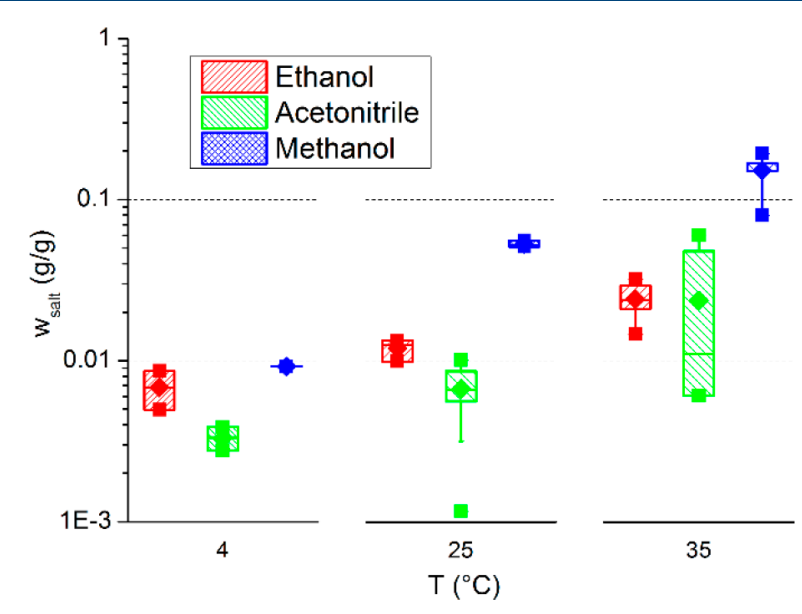

Figure 13. Box chart for the water solubility data: the diamond indicates the mean, the boxes dimensions, the center lines represent the 25 th -50 th -75 th percentiles, and the whiskers the 10th and 90th. Data taken with the IC method.

Rumpf et al. ${ }^{112}$ on the evaporation of water $-\mathrm{CO}_{2}-\mathrm{NH}_{3}$ mixtures as a general comparison. Anyway, the sublimation 


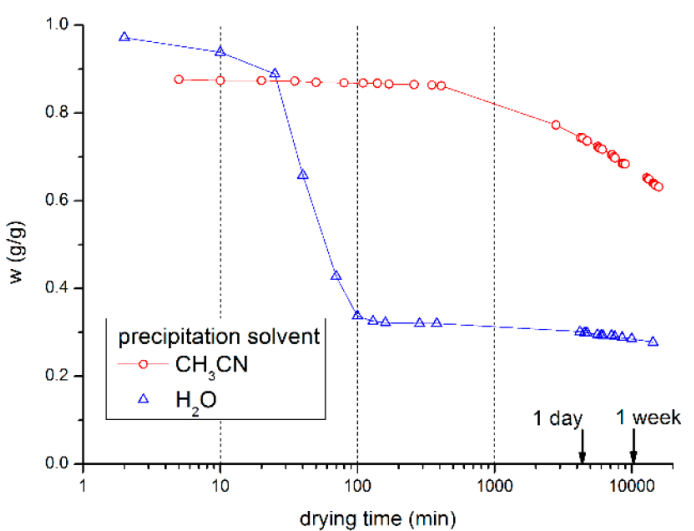

Figure 14. Normalized weights of two samples of ammonium bicarbonate precipitated from acetonitrile (circles) and water (triangles), filtered and exposed to air at ambient temperature.

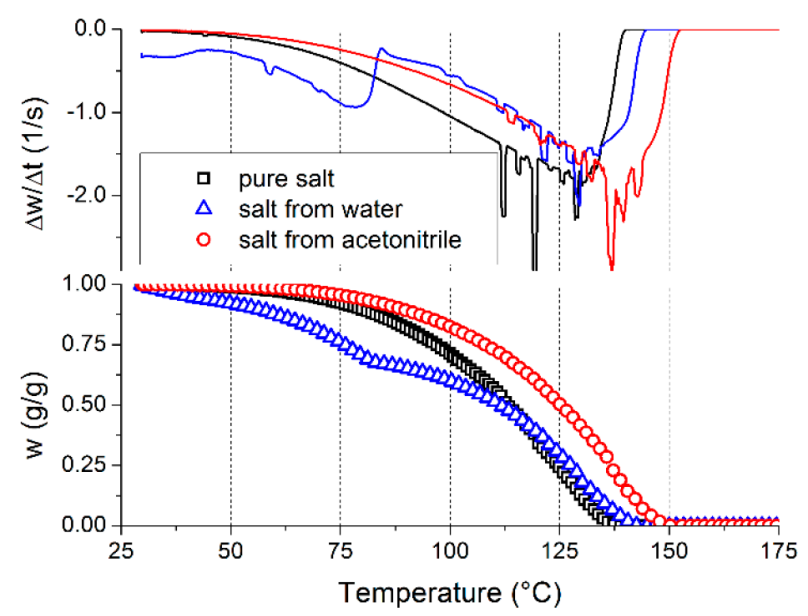

Figure 15. Thermogravimetric assays for pure ammonium bicarbonate and the salt precipitated from water/acetonitrile. Normalized weights in the bottom panel and derivative signal above.

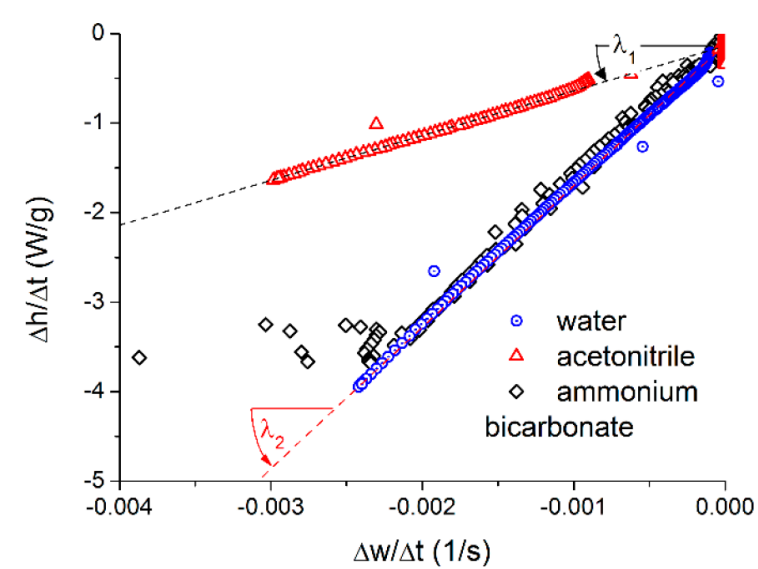

Figure 16. Pure species thermal analysis crossing the thermal signal and the mass loss derivative. The apparent latent heats from this kind of analysis are $\lambda_{1}=500 \mathrm{~J} / \mathrm{g}$ for acetonitrile and $\lambda_{2}=1580 \mathrm{~J} / \mathrm{g}$ for water and ammonium bicarbonate: the empirical calibration factor is then 67$69 \%$.

reaction yields $2.13 \mathrm{~kJ}$ per gram of solid, which is very near to the latent heat of water, as also suggested by the TGA analysis of Figure 16. The different data analysis of Figure 17 suggests two different sublimation regimes at the start and the end of the

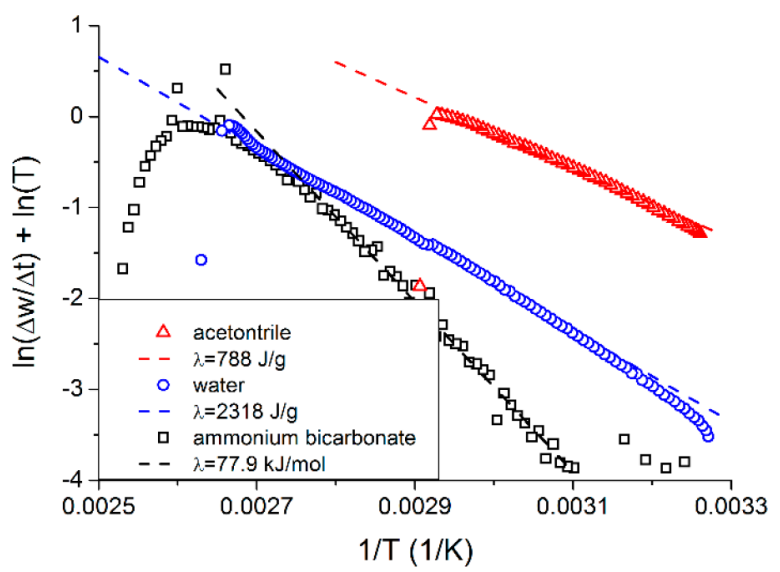

Figure 17. Latent heat of the pure species as retrieved extrapolating the saturation pressure (defined except for a calibration constant). Ammonium bicarbonate shows an initial latent heat of $78 \mathrm{~kJ} / \mathrm{mol}$ and a final one of $42 \mathrm{~kJ} / \mathrm{mol}$ (like water itself).

experiment, with a decreasing molar heat respect to a constant mass latent heat, as if the molecular weight of the substance leaving the crucible varied through time. See also the Supporting Information and the observation of Nowak and Skrzypek. ${ }^{87}$

Because ammonium bicarbonate behaves as water in the neat thermal output of TGA, the acetonitrile content of an aqueous phase can be guessed by applying the same heat balance of eq 2 for a binary mixture. Considering, moreover, that the salt decomposes into products much more volatile than acetonitrile itself, it is lost in the initial part of the assay, leaving pure water on the crucible when the TGA run approaches its end. This is shown in the integral heat plot of Figure 18. A binary acetonitrile-water mixture, an organic phase (rich in acetonitrile), and an aqueous one (rich in salt and water) behave in the same way at the higher evaporation temperatures, when only water is left; then the quantity of liquid, still present on the crucible at the onset of this final linear regime, represents the

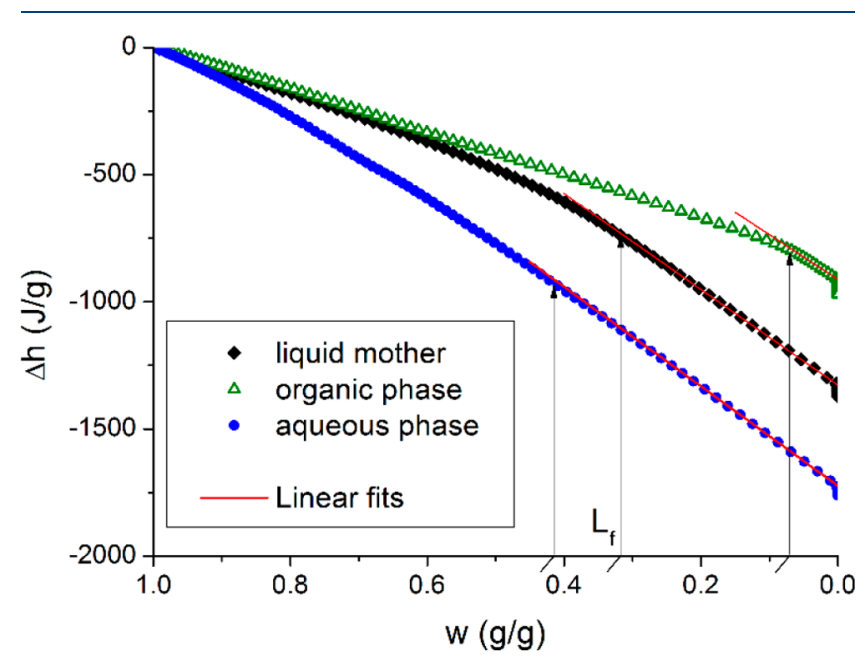

Figure 18. Integral heat signal of a TGA run plotted vs the mass still present on the open crucible. The slope of the final linear section represent a constant latent heat evaporation regime, in this case that of water. The earlier evaporation curve can be linear with a different slope, or bent, indicating the progressive loss of acetonitrile and ammonium bicarbonate along with water. The $y$-axis span of each curve is linearly related to the acetonitrile content, the "inflection" $x$-axis coordinate is a nonlinear function of the water content. 
water remaining after the other chemicals have been stripped. A numerical method to quantify the pure water in the original mixture starting from this kind of charts is in the Supporting Information; by applying this technique, it is possible in principle to obtain the water content independently, making the data analysis more robust. Nevertheless, the sensitivity of this method is limited, so its use to substitute the ${ }^{1} \mathrm{H}$ NMR and IC balances (rather than to check their consistency) was not systematic.

4.4. Comparison with Other Systems. According to the original experiments by Renard, the widest two-phase region (without solid precipitation) is obtained with potassium acetate, whereas the solubility of ammonium compounds it is very sensitive to the anion. $\mathrm{NaSO}_{4}$ is the salt, from those early experiments, with the boundary between the SLL and LL regions of the phase diagrams more similar to that in this work.

From the collection presented by Minglun, sodium and potassium chlorides behave like the ammonium bicarbonate system toward the water-rich end of the diagram, whereas all reviewed sulfates better approximate the acetonitrile-rich side. This suggests that the cation has a greater role in determining the acetonitrile content of the aqueous phase, and the anion the water residue in the organic phase.

In the original Renard's procedure, the binodal curves were used, together with the salt weighings and the overall system composition, to determine the phases compositions, whereas for this work, each phase was analyzed independently. Our data do not present any systematic mismatch between cloud-point measurements and phase-split experiments, as is instead the case for Minglun's sets. It is confirmed, anyway, that delays in the salt solvation during the different experiments and the order of addition and mixing of the chemicals must be taken into account. These observations could share some physical background with the explanation of Merchuk and co-workers about the "phase inversion time".

Both ammonium sulfate and nitrate behave differently with respect to ammonium bicarbonate, essentially for a much broader extension of the coexistence region along the salt-water side of the diagrams. The reviewed literature accounts for more than one hundred systems consisting of acetonitrile, water, and an inorganic compound, yet we are not aware of a quantitative study involving the hydrogen carbonate anion.

\section{CONCLUSIONS}

Original solid-liquid-liquid equilibrium data have been collected for a mixture of water, acetonitrile, and ammonium bicarbonate as the basis to interpret the features of multiphase reactors and of separation operation to resolve the acetonitrilewater azeotrope. Miscibility and solubility data are provided and interpreted.

Acetonitrile is not fully miscible in ammonium bicarbonate aqueous solutions. Beyond the critical point, the salt solubility itself in the aqueous phase decreases as the acetonitrile fraction increases. This phase equilibrium can find application in several fields, due to the established importance of acetonitrile as a solvent and of ammonium bicarbonate as a buffering system for organic applications. These data fill a gap in the already published solubility experiments.

The phase diagram of this system at ambient pressure is strongly influenced by the temperature: over a range of $35^{\circ} \mathrm{C}$, the salt total solubility increases from 4 to $5 \mathrm{wt} \%$ to more than 25 wt \%, appreciably widening the biphasic coexistence region. The acetonitrile fraction in the liquid phases, on the other hand, is nearly constant when the ionic strength is saturated. The organic phase shows a maximum acetonitrile fraction almost equal to the atmospheric azetrope with water $\left(0.693 \mathrm{~mol}_{\mathrm{a}} /\right.$ mol, ${ }^{113}$ i.e., $\left.83.7 \mathrm{wt} \%\right)$.

The relatively high water content in the organic phase does not seem to increase the salt solubility with respect to that in pure acetonitrile, indicating that the water molecules and the ions are likely coordinated independently by the acetonitrile, at least when the latter is not below 75 wt \% (57 mol \%).

The volumetric extraction efficiency exhibited by this salting out reaches $2 \mathrm{~mL}$ of organic phase per $1 \mathrm{~mL}$ of aqueous phase at saturated salt (starting from equal weights of acetonitrile and water in the liquid). This and other comparisons with already published acetonitrile salting-out cases confirm that the anion is likely the most important species in determining the tie-line width, with the cation and the temperature exerting bigger influence on the biphasic region depth.

The solubility of ammonium bicarbonate in water is consistent with previously published data, also if measured with different methods. The solubility in acetonitrile and ethanol is at least 1 order of magnitude smaller at every temperature investigated. The behavior in methanol is different, because the solubility shows a marked increased with temperature (at $4{ }^{\circ} \mathrm{C}$, methanol behaves like ethanol; at $35^{\circ} \mathrm{C}$, it behaves like water), indicating a greater importance of the enthalpy contribution to the ion solvation.

The published thermal data relative to ammonium bicarbonate itself are reviewed and complemented with new, independent measures of its sublimation heat. The presented experiments suggest that the liquid-phase chemistry of the $\mathrm{NH}_{3}-\mathrm{CO}_{2}-\mathrm{H}_{2} \mathrm{O}$ system (from which the solid formation energy is generally calculated) might be different from the "dry" behavior. It is possible that the solid sublimation is a multistep process, where $\mathrm{NH}_{3}$ and $\mathrm{CO}_{2}$ are lost first, leaving a residue of nearly pure water to evaporate later. The nonconstant stoichiometric composition of the sublimating substance and the latent heats of the different species would give a neat heat signal indistinguishable from that of water, whereas the proper analysis of the evaporation speed shows the phenomenon. This aspect is still open to further developments. The careful use of the thermogravimetric technique lets it possible to determine water independently, which is useful for a system where the salt nature poses problems with its drying and GC inspection; this field also deserves further work to overcome the sensitivity limits experienced so far.

\section{ASSOCIATED CONTENT}

\section{SI Supporting Information}

The Supporting Information is available free of charge at https://pubs.acs.org/doi/10.1021/acs.iecr.1c02249.

Analysis methods, experimental data, calorimetry, details of the UNIQUAC model, parameters for regression and UNIQUAC binary interaction parameters (PDF)

\section{AUTHOR INFORMATION}

\section{Corresponding Authors}

Antonio Tripodi - Chemical Plants and Industrial Chemistry Group, Department of Chemistry, Università degli Studi di Milano, Milano 20133, Italy; CNR-ISTM and INSTM Unit Milano-Università, Milano 20133, Italy;

Email: antonio.tripodi@guest.unimi.it 
Ilenia Rossetti - Chemical Plants and Industrial Chemistry Group, Department of Chemistry, Università degli Studi di Milano, Milano 20133, Italy; CNR-ISTM and INSTM Unit Milano-Università, Milano 20133, Italy; 으orcid.org/00000001-5882-5011; Email: ilenia.rossetti@unimi.it

\section{Authors}

Francesco Conte - Chemical Plants and Industrial Chemistry Group, Department of Chemistry, Università degli Studi di Milano, Milano 20133, Italy

Alessandro Robbiano - DICCA, Università degli Studi di Genova and INSTM Unit-Genova, Genoa 16100, Italy

Gianguido Ramis - DICCA, Università degli Studi di Genova and INSTM Unit-Genova, Genoa 16100, Italy

Complete contact information is available at: https://pubs.acs.org/10.1021/acs.iecr.1c02249

\section{Notes}

The authors declare no competing financial interest.

\section{ACKNOWLEDGMENTS}

The authors acknowledge the valuable help of Serena Cappelli (Università degli Studi di Milano) who performed all the TGA scans. The experiments took place in the "SmartMatLab" facility (funded by Fondazione CARIPLO) within the Department of Chemistry, Università degli Studi di Milano. ${ }^{1} \mathrm{H}$ NMR analyses were executed by Dr. Americo Costantino (Università degli Studi di Milano) within the same department. Dr. Sebastiano Tomassetti (Università Politecnica delle Marche) kindly assisted the implementation and troubleshooting of the UNIQUAC regression algorithm.

\section{ACRONYMS AND SYMBOLS}

\section{Formulas}

$a$ activity

$c_{\mathrm{p}}$ specific heat $(\mathrm{J} /(\mathrm{g} \mathrm{K}))$

$h$ specific enthalpy $(\mathrm{J} / \mathrm{g})$

$\mathcal{L}$ Letcher function

$m$ mass (g)

$\mathcal{M}$ Merchuck function

$n$ moles number

$P M$ molar weight $(\mathrm{g} / \mathrm{mol})$

$q$ UNIQUAC parameter

$R$ gas constant $(\mathrm{J} /(\mathrm{mol} \mathrm{K}))$

$t$ time (s)

$T$ temperature $(\mathrm{K})$

$w$ weight fraction $(\mathrm{g} / \mathrm{g})$

$x$ liquid fraction $(\mathrm{mol} / \mathrm{mol})$

$y$ vapor fraction $(\mathrm{mol} / \mathrm{mol})$

$\gamma$ activity coefficient

$\varphi$ UNIQUAC weighed parameter

$\lambda$ vaporization heat $(\mathrm{J} / \mathrm{g})$

$\theta$ UNIQUAC weighed parameter

$\psi$ UNIQUAC interaction term

$\rho$ UNIQUAC parameter

\section{Subscripts}

a acetonitrile

e ethanol

s salt

w water

$i, j, k$ species index

\section{Superscripts}

I heavy (aqueous) phase

II light (organic) phase

0 total mixture

$\mathrm{p}$ phase index

Text

IC ionic chromatography

HPLC high-performance liquid chromatography

${ }^{1} \mathrm{H}$ NMR proton nuclear magnetic resonance

TGA thermogravimetric analysis

UNIQUAC UNIversal QUAsi Chemical

\section{REFERENCES}

(1) Mainville, C. A.; Chatten, L. G. Scope of Acetonitrile as a Solvent in the Nonaqueous Titration of Organic Medicinals. J. Pharm. Sci. 1964, 53 (2), 154-157.

(2) Barwick, V. J. Strategies for Solvent Selection - A Literature Review. TrAC, Trends Anal. Chem. 1997, 16 (6), 293-309.

(3) Mcconvey, I. F.; Woods, D.; Lewis, M.; Gan, Q.; Nancarrow, P. The Importance of Acetonitrile in the Pharmaceutical Industry and Opportunities for Its Recovery from Waste. Org. Process Res. Dev. 2012, $16(4), 612-624$.

(4) Joshi, D. R.; Adhikari, N. An Overview on Common Organic Solvents and Their Toxicity. J. Pharm. Res. Int. 2019, 28 (3), 1-18.

(5) Huang, F.; Zheng, S.; Chen, Y.; Zhou, M.; Sun, X. Simulation and Optimization of Pressure-Swing Distillation System for High Purity Acetonitrile. 2016, 58 (Msota), 96-100.

(6) Tripodi, A.; Manzini, D.; Compagnoni, M.; Ramis, G.; Rossetti, I. Alternative Integrated Distillation Strategies for the Purification of Acetonitrile from Ethanol Ammoxidation. J. Ind. Eng. Chem. 2018, 59, $35-49$.

(7) Sharma, B.; Singh, N.; Jain, T.; Kushwaha, J. P.; Singh, P. Acetonitrile Dehydration via Extractive Distillation Using Low Transition Temperature Mixtures as Entrainers. J. Chem. Eng. Data 2018, 63 (8), 2921-2930.

(8) Qi, J.; Li, Y.; Xue, J.; Qiao, R.; Zhang, Z.; Li, Q. Comparison of Heterogeneous Azeotropic Distillation and Energy-Saving Extractive Distillation for Separating the Acetonitrile-Water Mixtures. Sep. Purif. Technol. 2020, 238, 116487.

(9) Sohio Acrylonitrile Process. American Chemical Society. https:// www.acs.org/content/acs/en/education/whatischemistry/ landmarks/acrylonitrile.html.

(10) Tollefson, E. L.; Decker, R. M.; Johnson, C. B. Development of a Process for Production of Acetonitrile from Acetic Acid and Ammonia. Can. J. Chem. Eng. 1970, 48, 219-223.

(11) Rojas, E.; Guerrero-Pérez, M. O.; Bañares, M. A. Direct Ammoxidation of Ethane: An Approach to Tackle the Worldwide Shortage of Acetonitrile. Catal. Commun. 2009, 10 (11), 1555-1557.

(12) Hamill, C.; Driss, H.; Goguet, A.; Burch, R.; Petrov, L.; Daous, M.; Rooney, D. Mild Temperature Palladium-Catalyzed Ammoxidation of Ethanol to Acetonitrile. Appl. Catal., A 2015, 506, 261-267.

(13) Folco, F. Catalytic Processes for the Transformation of Ethanol into Acetonitrile. Dissertation Thesis; Università di Bologna, Bologna, Italy, 2013.

(14) Tripodi, A.; Ripamonti, D.; Martinazzo, R.; Folco, F.; Tabanelli, T.; Cavani, F.; Rossetti, I. Kinetic Model for the Ammoxidation of Ethanol to Acetonitrile. Chem. Eng. Sci. 2019, 207, 862-875.

(15) Galanov, S. I.; Sidorova, O. I.; Gavrilenko, M. A. The Process of Acetonitrile Synthesis over $\gamma$-Al2O3 Promoted by Phosphoric Acid Catalysts. Procedia Chem. 2014, 10, 108-113.

(16) Stepnowski, P.; Blotevogel, K. H.; Ganczarek, P.; Fischer, U.; Jastorff, B. Total Recycling of Chromatographic Solvents-Applied Management of Methanol and Acetonitrile Waste. Resour. Conserv. Recycl. 2002, 35 (3), 163-175.

(17) Wang, N.; Ye, Q.; Chen, L.; Zhang, H.; Zhong, J. Application of Heat Pump Technology to Recover 1,4-Dioxane and Acetonitrile from 
Wastewater via Triple-Column Distillation. Appl. Therm. Eng. 2021, 190 (March), 116802.

(18) Liang, J.; Wang, H.; Wang, Z.; Baena-Moreno, F. M.; SebastiaSaez, D.; Li, C. Optimal Separation of Acetonitrile and Pyridine from Industrial Wastewater. Chem. Eng. Res. Des. 2021, 169 (8), 54-65.

(19) Mendonca da Silva Amorim, P.; Busko Di Vitta, P.; Converti, A.; Pinheiro de Souza Oliveira, R. Acetonitrile Recovery by Distillation Techniques Combined with Salting-Out or Sugaring-Out in Tandem. Chem. Eng. Technol. 2021, 44, 639-647.

(20) Di Cave, S.; Mazzarotta, B. Isobaric Vapor-Liquid Equilibria for the Binary Systems Formed by Acetonitrile and Aromatic Hydrocarbons. J. Chem. Eng. Data 1991, 36 (3), 293-297.

(21) Khurma, J. R.; Muthu, O.; Munjal, S.; Smith, B. D. Total-Pressure Vapor-Liquid Equilibrium Data for Binary Systems of Dichloromethane with Pentane, Acetone, Ethyl Acetate, Methanol, and Acetonitrile. J. Chem. Eng. Data 1983, 28 (4), 412-419.

(22) Narasigadu, C. Phase Equilibrium Investigation of the Water and Acetonitrile Solvent with Heavy Hydrocarbons. Master's Thesis; University of KwaZulu Natal, Durban, South Africa, 2006.

(23) Li, J.; Yang, X.; Chen, K.; Zheng, Y.; Peng, C.; Liu, H. Sifting Ionic Liquids as Additives for Separation of Acetonitrile and Water Azeotropic Mixture Using the COSMO-RS Method. Ind. Eng. Chem. Res. 2012, 51, 9376.

(24) Li, J.; Li, J.; Zheng, Y.; Peng, C.; Liu, H. Measurement and Correlation of Isobaric Vapour-Liquid Equilibrium for the (Acetonitrile + water) System Containing Different Ionic Liquids at Atmospheric Pressure. J. Chem. Thermodyn. 2019, 138, 366-373.

(25) Li, J.; Li, T.; Peng, C.; Liu, H. Extractive Distillation with Ionic Liquid Entrainers for the Separation of Acetonitrile and Water. Ind. Eng. Chem. Res. 2019, 58 (14), 5602-5612.

(26) Sharma, B.; Singh, N.; Kushwaha, J. P. Ammonium-Based Deep Eutectic Solvent as Entrainer for Separation of Acetonitrile-Water Mixture by Extractive Distillation. J. Mol. Liq. 2019, 285, 185-193.

(27) Fang, J.; Zhao, R.; Wang, H.; Li, C.; Liu, J. Salting-out Effect of Ionic Liquids on Isobaric Vapor-Liquid Equilibrium of AcetonitrileWater System. Chin. J. Chem. Eng. 2015, 23 (8), 1369-1373.

(28) You, X.; Gu, J.; Gerbaud, V.; Peng, C.; Liu, H. Optimization of Pre-Concentration, Entrainer Recycle and Pressure Selection for the Extractive Distillation of Acetonitrile-Water with Ethylene Glycol. Chem. Eng. Sci. 2018, 177, 354-368.

(29) Acosta, J.; Arce, A.; Rodil, E.; Soto, A. A Thermodynamic Study on Binary and Ternary Mixtures of Acetonitrile, Water and Butyl Acetate. Fluid Phase Equilib. 2002, 203 (1-2), 83-98.

(30) Taha, M.; Teng, H. L.; Lee, M. J. Phase Diagrams of Acetonitrile or (Acetone + Water + EPPS) Buffer Phase Separation Systems at 298.15 K and Quantum Chemical Modeling. J. Chem. Thermodyn. 2012, 54, 134-141.

(31) Oence, D. N.; Gu, T. Liquid-Liquid Equilibrium of the Acetonitrile-Water System for Protein Purification. Sep. Technol. 1996, 6 (4), 261-264.

(32) Schneider, G. Druckeinfluß Auf Die Entmischung Flüssiger Systeme III. Das 4-Phasengleichgewicht Flüssig-Flüssig-Iest-Fest Im System Acetonitril-H20 Bei $-24.2^{\circ} \mathrm{C}$ Und 1240 bar. Z. Phys. Chem. 1964, 41, 327-338.

(33) Shao, G.; Agar, J.; Giese, R. W. Cold-Induced Aqueous Acetonitrile Phase Separation. J. Chromatogr A 2017, 1506 (1), 128133.

(34) Szydłowski, J.; Szykuła, M. Isotope Effect on Miscibility of Acetonitrile and Water. Fluid Phase Equilib. 1999, 154 (1), 79-87.

(35) Renard, J. A.; Oberg, A. G. Ternary Systems: Water-AcetonitrileSalts. J. Chem. Eng. Data 1965, 10 (2), 152-155.

(36) Renard, J. A. Ternary Systems: Water-Acetonitrile-Salts. J. Chem. Eng. Data 1966, 11 (2), 169-171.

(37) Renard, J. A.; Heichelheim, H. R. Ternary Systems WaterAcetonitrile-Salts. J. Chem. Eng. Data 1967, 12 (1), 33-36.

(38) Renard, J. A.; Heichelheim, H. R. Ternary Systems: WaterAcetonitrile-Salts. J. Chem. Eng. Data 1968, 13 (4), 485-488.
(39) Cannon, S. L. Liquid-Liquid Equilibrium in the System Acetonitrile-Water-Salt by Infrared Spectroscopy. Thesis; Texas Tech University, Lubbock, TX, 1969.

(40) Nagaosa, Y. Salting-out of Polar Solvents from Aqueous Solution and Its Application to Ion-Pair Extractions. Anal. Chim. Acta 1980, 120, 279-287.

(41) Smotrov, M. P.; Cherkasov, D. G.; Kurskii, V. F.; Il'In, K. K. Topological Transformation of the Phase Diagram of the Lithium Nitrate-Water-Acetonitrile Ternary System within the Range of -20 to $50^{\circ} \mathrm{C}$. Russ. J. Inorg. Chem. 2014, 59 (9), 1015-1025.

(42) Takamuku, T.; Yamaguchi, A.; Matsuo, D.; Tabata, M.; Kumamoto, M.; Nishimoto, J.; Yoshida, K.; Yamaguchi, T.; Nagao, M.; Otomo, T.; Adachi, T. Large-Angle X-Ray Scattering and SmallAngle Neutron Scattering Study on Phase Separation of AcetonitrileWater Mixtures by Addition of NaCl. J. Phys. Chem. B 2001, 105 (26), 6236-6245.

(43) An, N.; Zhuang, B.; Li, M.; Lu, Y.; Wang, Z.-G. Combined Theoretical and Experimental Study of Refractive Indices of WaterAcetonitrile-Salt Systems. J. Phys. Chem. B 2015, 119 (33), 1070110709.

(44) Li, M.; Zhuang, B.; Lu, Y.; An, L.; Wang, Z. G. Salt-Induced Liquid-Liquid Phase Separation: Combined Experimental and Theoretical Investigation of Water-Acetonitrile-Salt Mixtures. J. Am. Chem. Soc. 2021, 143 (2), 773-784.

(45) Skrzecz, A.; Lisov, N. I.; Sazonov, N. V. IUPAC-NIST Solubility Data Series. 83. Acetonitrile: Ternary and Quaternary Systems. J. Phys. Chem. Ref. Data 2007, 36 (3), 733-1131.

(46) Jones, L. A.; Prabel, J. B.; Glennon, J. J.; Copeland, M. F.; Kavlock, R. J. Extraction of Phenol and Its Metabolites from Aqueous Solution. J. Agric. Food Chem. 1993, 41 (5), 735-741.

(47) Nemati-Kande, E.; Shekaari, H. Salting-out Effect of Sodium, Potassium, Carbonate, Sulfite, Tartrate and Thiosulfate Ions on Aqueous Mixtures of Acetonitrile or 1-Methyl-2-Pyrrolidone: A Liquid-Liquid Equilibrium Study. Fluid Phase Equilib. 2013, 360, 357-366.

(48) Niu, Z.; Yu, C.; He, X.; Zhang, J.; Wen, Y. Salting-out Assisted Liquid-Liquid Extraction Combined with Gas Chromatography-Mass Spectrometry for the Determination of Pyrethroid Insecticides in High Salinity and Biological Samples. J. Pharm. Biomed. Anal. 2017, 143, 222-227.

(49) Díez, C.; Traag, W. A.; Zommer, P.; Marinero, P.; Atienza, J. Comparison of an Acetonitrile Extraction/Partitioning and "Dispersive Solid-Phase Extraction" Method with Classical Multi-Residue Methods for the Extraction of Herbicide Residues in Barley Samples. J. Chromatogr. A 2006, 1131 (1-2), 11-23.

(50) Nanita, S. C.; Padivitage, N. L. T. Ammonium Chloride Salting out Extraction/Cleanup for Trace-Level Quantitative Analysis in Food and Biological Matrices by Flow Injection Tandem Mass Spectrometry. Anal. Chim. Acta 2013, 768 (1), 1-11.

(51) Dhamole, P. B.; Mahajan, P.; Feng, H. Sugaring out: A New Method for Removal of Acetonitrile from Preparative RP-HPLC Eluent for Protein Purification. Process Biochem. 2010, 45 (10), 1672-1676.

(52) Jafari, S. A.; Entezari, M. H. Salting out in ACN/Water Systems: Hofmeister Effects and Partition of Quercetin. J. Mol. Liq. 2020, 312, 113331.

(53) Yoshida, M.; Akane, A.; Nishikawa, M.; Watabiki, T.; Tsuchihashi, H. Extraction of Thiamylal in Serum Using Hydrophilic Acetonitrile with Subzero-Temperature and Salting-out Methods. Anal. Chem. 2004, 76 (16), 4672-4675.

(54) Santos, P. L.; Santos, L. N. S.; Souza, I. N.; Souza, R. L.; Soares, C. M. F.; Lima, A. S. Acetonitrile and $\mathrm{Na}+$ or $\mathrm{K}+$ Salts as Constituents of the Aqueous Two- Phase System: Equilibrium Data and Capsaicin Puri Fi Cation. J. Chem. Eng. Data 2019, 64, 4132.

(55) Moravcová, D.; Cmelík, R.; Křenková, J. No-Additive Salting-out Liquid-Liquid Extraction-A Tool for Purification of Positively Charged Compounds from Highly Salted Reaction Mixtures. J. Sep. Sci. 2020, 43 (23), 4356-4363.

(56) Gupta, B. S.; Fang, M. Y.; Taha, M.; Lee, M. J. Separation of 1,3Dioxolane, 1,4-Dioxane, Acetonitrile and Tert-Butanol from Their 
Aqueous Solutions by Using Good's Buffer HEPES-Na as an Auxiliary Agent. J. Taiwan Inst. Chem. Eng. 2016, 66, 43-53.

(57) Valente, I. M.; Gonçalves, L. M.; Rodrigues, J. A. Another Glimpse over the Salting-out Assisted Liquid-Liquid Extraction in Acetonitrile/Water Mixtures. J. Chromatogr. A 2013, 1308, 58-62.

(58) Tandel, D.; Shah, P.; Patel, K.; Thakkar, V.; Patel, K.; Gandhi, T. Salting-out Assisted Liquid-Liquid Extraction for Quantification of Febuxostat in Plasma Using RP-HPLC and Its Pharmacokinetic Application. J. Chromatogr. Sci. 2016, 54 (10), 1827-1833.

(59) Qiu, Z.; Yu, J.; Dai, Y.; Yang, Y.; Lu, X.; Xu, J.; Qin, Z.; Huang, F.; Li, N. A Simple LC-MS/MS Method Facilitated by Salting-out Assisted Liquid-Liquid Extraction to Simultaneously Determine Trans-Resveratrol and Its Glucuronide and Sulfate Conjugates in Rat Plasma and Its Application to Pharmacokinetic Assay. Biomed. Chromatogr. 2017, 31 (11), e4001.

(60) Zhang, L. A New Liquid-Liquid Partitioning System for Bioseparations at Low Temperatures. Master's Thesis; Ohio University, Athens, OH, 1997.

(61) Peng, L.; Rustamov, I.; Loo, L.; Farkas, T. Improved Results for LC/MS of Basic Compounds Using High PH Mobile Phase on a Gemini C18 Column; Phenomenex: Torrance, CA.

(62) Liu, Y.; Ding, Y.; Song, Y.; Guo, X. Enantioseparation and Determination of Orphenadrine in Rat Plasma and Its Application to a Stereoselective Pharmacokinetic Study. New J. Chem. 2021, 45, 5428.

(63) Dolan, J. A Guide to HPLC and LC-MS Buffer Selection; ACE: Aberdeen, Scotland, 2012.

(64) Hägele, J. S.; Basrak, M.; Schmid, M. G. Enantioselective Separation of Novel Psychoactive Substances Using a Lux® AMP $3 \mu \mathrm{m}$ Column and HPLC-UV. J. Pharm. Biomed. Anal. 2020, 179, 112967.

(65) Espada, A.; Rivera-Sagredo, A. Ammonium Hydrogencarbonate, an Excellent Buffer for the Analysis of Basic Drugs by Liquid Chromatography-Mass Spectrometry at High PH. J. Chromatogr. A 2003, 987 (1-2), 211-220.

(66) Ammonium Bicarbonate. PubChem. https://pubchem.ncbi.nlm. nih.gov/compound/Ammonium-bicarbonate.

(67) Zhang, Y.; Feng, D.; Gao, J.; Du, Q.; Wu, S. Thermodynamic Properties in Ternary System of NH 4 HCO 3 -H 2 O-Ethanol Based on Antisolvent Method to Strengthen Crystallization of Carbonized Ammonia. Adsorpt. Sci. Technol. 2019, 37 (1-2), 127-138.

(68) Verbrugge, P. Vapour-Liquid Equilibria of the Ammonia-Carbon Dioxide-Water System. PhD Thesis; University of Delft, Delft, The Netherlands, 1979145

(69) Kurz, F.; Rumpf, B.; Maurer, G. Vapor-Liquid-Solid Equilibria in the System NH3-CO2-H2O from around 310 to $470 \mathrm{~K}$ : New Experimental Data and Modeling. Fluid Phase Equilib. 1995, 104 (C), 261-275.

(70) Darde, V.; Van Well, W. J. M. M.; Stenby, E. H.; Thomsen, K. Modeling of Carbon Dioxide Absorption by Aqueous Ammonia Solutions Using the Extended UNIQUAC Model. Ind. Eng. Chem. Res. 2010, 49 (24), 12663-12674.

(71) Darde, V.; Thomsen, K.; van Well, W. J.M.; Bonalumi, D.; Valenti, G.; Macchi, E. Comparison of Two Electrolyte Models for the Carbon Capture with Aqueous Ammonia. Int. J. Greenhouse Gas Control 2012, 8, 61-72.

(72) Pazuki, G. R.; Pahlevanzadeh, H.; Ahooei, A. M. Prediction of Phase Behavior of CO2-NH3-H $2 \mathrm{O}$ System by Using the UNIQUACNon Random Factor (NRF) Model. Fluid Phase Equilib. 2006, 242 (1), 57-64.

(73) Milella, F.; Mazzotti, M. Estimating Speciation of Aqueous Ammonia Solutions of Ammonium Bicarbonate: Application of Least Squares Methods to Infrared Spectra. React. Chem. Eng. 2019, 4 (7), $1284-1302$.

(74) Sutter, D.; Gazzani, M.; Mazzotti, M. Formation of Solids in Ammonia-Based CO2capture Processes - Identification of Criticalities through Thermodynamic Analysis of the CO2-NH3-H2O System. Chem. Eng. Sci. 2015, 133, 170-180.

(75) Sutter, D.; Gazzani, M.; Mazzotti, M. A Low-Energy Chilled Ammonia Process Exploiting Controlled Solid Formation for PostCombustion CO 2 Capture. Faraday Discuss. 2016, 192, 59-83.
(76) Cooperative Research Centre for Coal in Sustainable Development, Research Report 68, 2006.

(77) Zhang, M.; Guo, Y. Process Simulations of Large-Scale CO2 Capture in Coal-Fired Power Plants Using Aqueous Ammonia Solution. Int. J. Greenhouse Gas Control 2013, 16, 61-71.

(78) Qi, G.; Wang, S.; Yu, H.; Feron, P.; Chen, C. Rate-Based Modeling of CO2absorption in Aqueous NH3in a Packed Column. Energy Procedia 2013, 37 (x), 1968-1976.

(79) Gaspar, J.; Arshad, M. W.; Blaker, E. A.; Langseth, B.; Hansen, T.; Thomsen, K.; von Solms, N.; Fosbøl, P. L. A Low Energy Aqueous Ammonia CO2 Capture Process. Energy Procedia 2014, 63, 614-623.

(80) Bak, C.; Asif, M.; Kim, W. Experimental Study on CO2 Capture by Chilled Ammonia Process. Chem. Eng. J. 2015, 265, 1-8.

(81) Zhu, Z. L.; Chen, D. L. Nitrogen Fertilizer Use in China Contributions to Food Production, Impacts on the Environment and Best Management Strategies. Nutr. Cycling Agroecosyst. 2002, 63 (2-3), 117-127.

(82) Zhuang, Q.; Clements, B.; Li, Y. From Ammonium Bicarbonate Fertilizer Production Process to Power Plant CO 2 Capture. Int. J. Greenhouse Gas Control 2012, 10, 56-63.

(83) Bulánek, R.; Novoveská, K.; Wichterlová, B. Oxidative Dehydrogenation and Ammoxidation of Ethane and Propane over Pentasil Ring Co-Zeolites. Appl. Catal., A 2002, 235 (1-2), 181-191.

(84) Folco, F.; Velasquez Ochoa, J.; Cavani, F.; Ott, L.; Janssen, M. Ethanol Gas-Phase Ammoxidation to Acetonitrile. Catal. Sci. Technol. 2017, 7, 200-212.

(85) Tripodi, A.; Bahadori, E.; Cespi, D.; Passarini, F.; Cavani, F.; Tabanelli, T.; Rossetti, I. Acetonitrile from Bioethanol Ammoxidation: Process Design from the Grass-Roots and Life Cycle Analysis. ACS Sustainable Chem. Eng. 2018, 6, 5441-5451.

(86) Nguyen, T. T. H.; Aras, G.; Vogel, G. H. Synthesis of Acetonitrile from Ammonium Acetate. Chem. Ing. Tech. 2014, 86, 161-168.

(87) Nowak, P.; Skrzypek, J. The Kinetics of Chemical Decomposition of Ammonium Bicarbonate and Carbonate in Aqueous Solutions. Chem. Eng. Sci. 1989, 44 (10), 2375.

(88) Sutter, D.; Mazzotti, M. Solubility and Growth Kinetics of Ammonium Bicarbonate in Aqueous Solution. Cryst. Growth Des. 2017, 17 (6), 3048-3054.

(89) Rossetti, I.; Tripodi, A. Batch Distillation and Vapor-Liquid Equilibrium of Acetonitrile and Water through Thermo-Gravimetric Analysis. In Chemical Engineering Greetings to Prof. Laura Annamaria Pellegrini on Occasion of her 65th Birthday; Masi, M., De Guido, G., Moioli, S., Eds.; AIDIC: Milan, Italy, 2020.

(90) Tripodi, A.; Rossetti, I. Aspects of the Thermo-Gravimetric Analysis of Liquid Mixtures as Predictive or Interpretation Tool for Batch Distillation. J. Therm. Anal. Calorim. 2021, DOI: 10.1007/ s10973-021-10990-1.

(91) Othmer, D. F.; Tobias, E. TIE LINE CORRELATION. Ind. Eng. Chem. 1942, 34 (6), 693-696.

(92) Bachman, I. Tie Lines in Ternary Liquid Systems. Ind. Eng. Chem., Anal. Ed. 1940, 12 (1), 38-39.

(93) Hand, D. B. Dineric Distribution. J. Phys. Chem. 1930, 34 (9), 1961-2000.

(94) Hlavatý, K. Correlation of the Binodal Curve in a Ternary Liquid Mixture with One Pair of Immiscible Liquids. Collect. Czech. Chem. Commun. 1972, 37 (12), 4005-4007.

(95) Letcher, T. M.; Siswana, P. M.; Van Der Watt, P.; Radloff, S. Phase Equilibria for (an Alkanol+ p-Xylene + Water) at $298.2 \mathrm{~K}$. J. Chem. Thermodyn. 1989, 21, 1053-1060.

(96) Merchuk, J. C.; Andrews, B. A.; Asenjo, J. A. Aqueous Two-Phase Systems for Protein Separation. J. Chromatogr., Biomed. Appl. 1998, 711, 285-293.

(97) Weber, H. C.; Meissner, P. Thermodynamics for Chemical Engineers, II; John Wiley \& Sons: New York, 1957.

(98) Anderson, T. F.; Prausnitz, J. M. Application of the UNIQUAC Equation to Calculation of Multicomponent Phase Equilibria. 1. VaporLiquid Equilibria. Ind. Eng. Chem. Process Des. Dev. 1978, 17 (4), 552561. 
(99) Thomsen, K.; Iliuta, M. C.; Rasmussen, P. Extended UNIQUAC Model for Correlation and Prediction of Vapor-Liquid-Liquid-Solid Equilibria in Aqueous Salt Systems Containing Non-Electrolytes. Part B. Alcohol (Ethanol, Propanols, Butanols)-Water-Salt Systems. Chem. Eng. Sci. 2004, 59 (17), 3631-3647.

(100) Choi, J. S.; Park, D. W.; Rhim, J. N. Application of NRTL and Uniquac Models to Liquid-Liquid Systems with Halogen Salts (Part I). Korean J. Chem. Eng. 1987, 4 (2), 161-169.

(101) Sorensen, J. M.; Magnussen, T.; Rasmussen, P.; Fredenslund, A. LIQUID-LIQUID EQUILIBRIUM DATA: THEIR RETRIEVAL, CORRELATION AND PREDICTION PART II: Correlation. Fluid Phase Equilib. 1979, 3, 47-82.

(102) Tomassetti, S.; Di Nicola, G.; Santori, G. Identification of UNIQUAC Binary Interaction Parameters in Liquid-Liquid Equilibrium. Fluid Phase Equilib. 2020, 510, 112483.

(103) Belda Maximino, R. Surface Tension and Density of Binary Mixtures of Monoalcohols, Water and Acetonitrile: Equation of Correlation of the Surface Tension. Phys. Chem. Liq. 2009, 47 (5), 475-486.

(104) Aminabhavi, T. M.; Gopalakrishna, B. Density, Viscosity, Refractive Index, and Speed of Sound in Aqueous Mixtures of N,NDimethylformamide, Dimethyl Sulfoxide, N,N-Dimethylacetamide, Acetonitrile, Ethylene Glycol, Diethylene Glycol, 1,4-Dioxane, Tetrahydrofuran, 2-Methoxyethanol, and 2-Ethox. J. Chem. Eng. Data 1995, 40 (4), 856-861.

(105) Cunningham, G. P.; Vidulich, G. A.; Kay, R. L. Several Properties Of Acetonitrile-Water, Acetonitrile-Methanol, and Ethylene Carbonate-Water Systems. J. Chem. Eng. Data 1967, 12 (3), 336-337.

(106) Kiyama, R.; Minomura, S. A Note on the Stability of Ammonium Bicarbonate Tablets. Rev. Phys. Chem. Japan 1952, 22 (1), 43-45.

(107) Langmuir, I. The Vapor Pressure of Metallic Tungsten. Phys. Rev. 1913, 2 (5), 329.

(108) Price, D. M. A Fit of the Vapours. Thermochim. Acta 2015, 622, 44-50.

(109) Barontini, F.; Cozzani, V. Assessment of Systematic Errors in Measurement of Vapor Pressures by Thermogravimetric Analysis. Thermochim. Acta 2007, 460 (1-2), 15-21.

(110) Pieterse, N.; Focke, W. W. Diffusion-Controlled Evaporation through a Stagnant Gas: Estimating Low Vapour Pressures from Thermogravimetric Data. Thermochim. Acta 2003, 406, 191-198.

(111) Que, H.; Chen, C.-C. Thermodynamic Modeling of the NH3 $\mathrm{CO} 2$ - H2O System with Electrolyte NRTL Model. Ind. Eng. Chem. Res. 2011, 50 (19), 11406-11421.

(112) Rumpf, B.; Weyrich, F.; Maurer, G. Enthalpy Changes upon Partial Evaporation of Aqueous Solutions Containing Ammonia and Carbon Dioxide. Ind. Eng. Chem. Res. 1998, 37 (8), 2983-2995.

(113) Vahdat, N.; Sather, G. A. Prediction of Multicomponent Azeotrope Composition and Temperature. Chem. Eng. J. 1985, 31 (2), 83-96. 